University of Redlands

\title{
Web GIS for Eelgrass Research
}

A Major Individual Project submitted in partial satisfaction of the requirements

for the degree of Master of Science in Geographic Information Systems

by

Matthew Meuser

Ruijin Ma, Ph.D., Committee Chair

Douglas M. Flewelling, Ph.D.

December 2015 
Web GIS for Eelgrass Research

Copyright (C) 2015

by

Matthew Meuser 
The report of Matthew Meuser is approved.
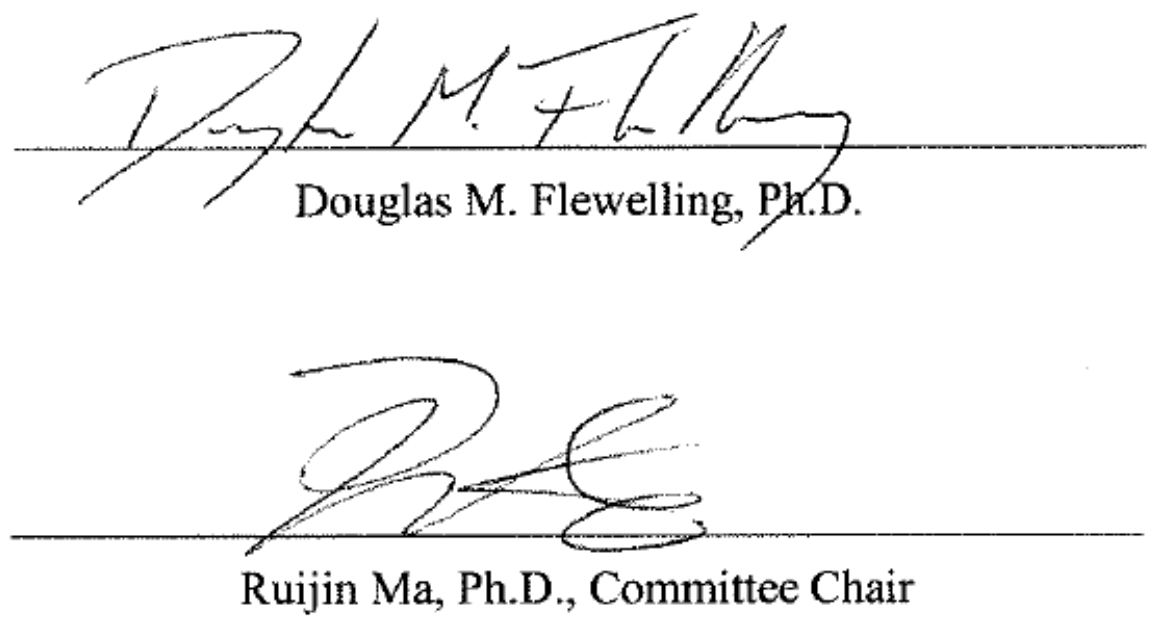

December 2015 



\section{Acknowledgements}

I would first like to acknowledge the members of Cohort 26 for their amazing persistence and spirit through the MS GIS Program over the last 12 months. What we have accomplished together is truly remarkable and I could not have assembled a more memorable group. I would like thank Shilpi Jain for taking time from her schedule to teach and mentor me on the principles of web development. Jian Ping Sim, I will be forever grateful for your help mentoring me through our rigorous class schedule and for becoming a dear friend I will miss greatly until we meet again. Thank you for the friendship of your kind and generous family. Arunabha Chowdhury, I am blessed to have been your roommate for this program. I cherish our friendship and will never take for granted how lucky I was to have lived with a best friend.

Thank you to the MS GIS faculty. Your wealth of knowledge and the effort you collectively commit to the students is the best in GIS. Dr. Ruijin Ma, I will be forever grateful for your patience as my advisor. You have taught me how to become dedicated and committed again. You will always be a mentor and someone I look up to. Thank you Dr. Flewelling for leading a world class program. Thank you, Andrea Barrios. I am proud to be in your first full Cohort.

Thank you to my family, the Meusers. This turned out to be a collective effort and without your support this project would not reach completion. Lindsey Zehner, you are the special someone in my life. Thank you for your continued support through the pursuit of my dream. 



\section{Abstract \\ Web GIS for Eelgrass Research}

by

Matthew Meuser

Eelgrass is vital to coastal and marine health. Recognizing and understanding the significance of eelgrass die-offs in San Juan County is essential to identifying potential causes. Eelgrass beds provide habitats for many commercial costal fish and represent immense economic and ecological value. This document details a Web GIS application developed to help monitor the environmental condition of eelgrass and perform data management and spatial analysis in the San Juan Islands with the collaboration of scholars from the University of Redlands. A File Geodatabase was built to store the client's data and then a web GIS application was developed using the ArcGIS API for JavaScript. The application was customized to enable the client to add new sampling sites, types of measurements, sampling values, view and query records, and visualize data using Esri's Heat Map Renderer from the JavaScript API. 



\section{Table of Contents}

Chapter 1 - Introduction ......................................................................................................... 1

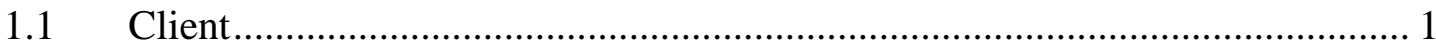

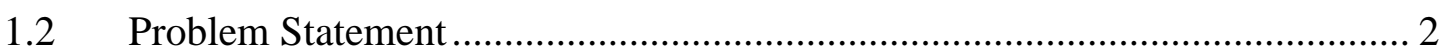

1.3 Proposed Solution ................................................................................... 2

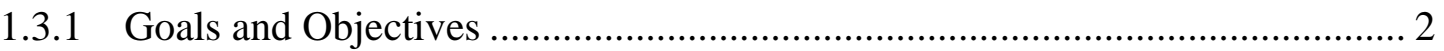

1.3.2 Scope

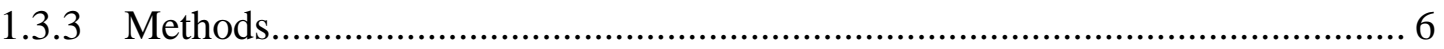

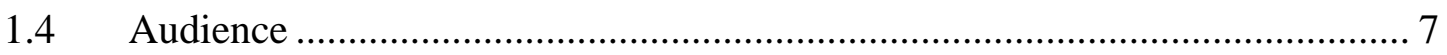

1.5 Overview of the Rest of This Report ............................................................. 7

Chapter 2 - Background and Literature Review ............................................................... 9

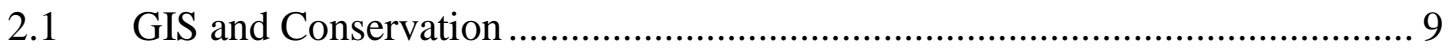

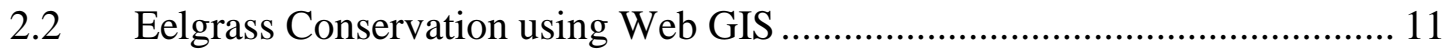

2.3 Spatial Data Sharing …………………………..................................... 13

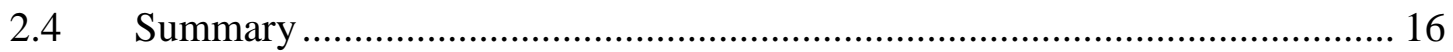

Chapter 3 - Systems Analysis and Design........................................................................... 19

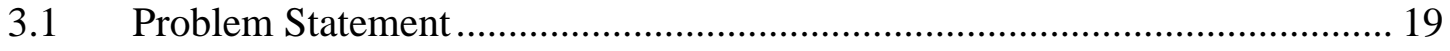

3.2 Requirements Analysis …………………………............................... 20

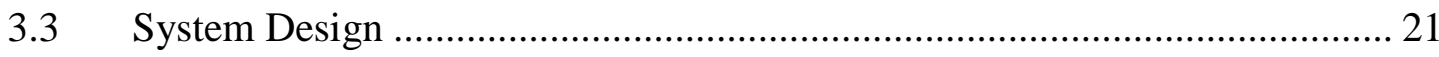

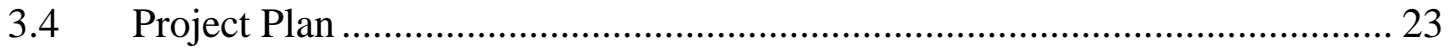

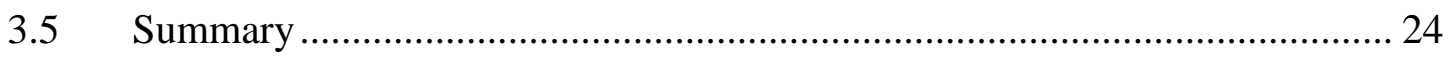

Chapter 4 - Database Design..................................................................................................... 25 


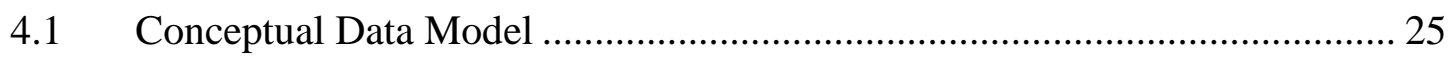

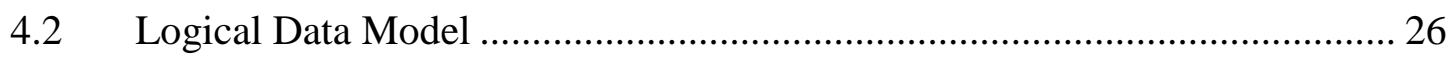

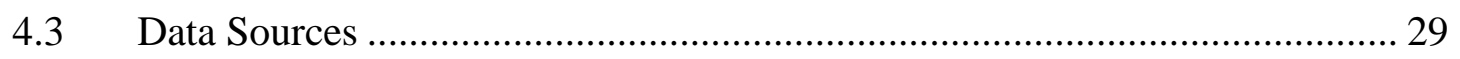

4.4 Data Scrubbing and Loading ............................................................ 31

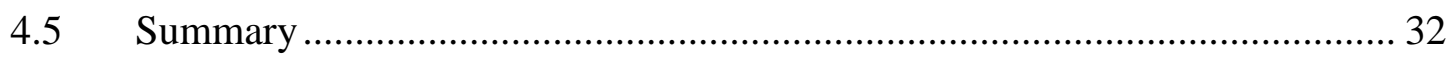

Chapter 5 - Implementation.................................................................................................... 33

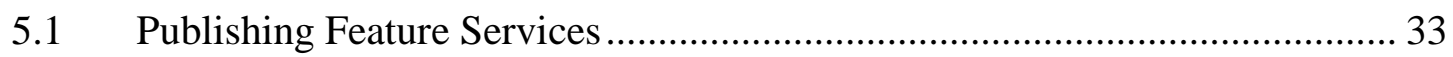

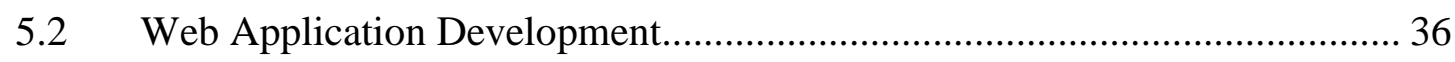

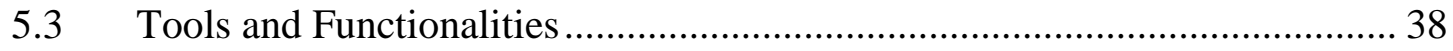

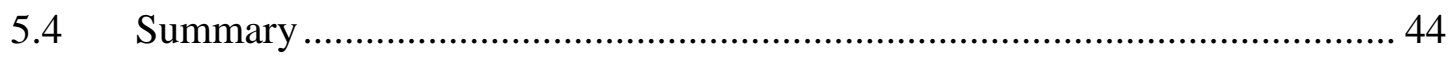

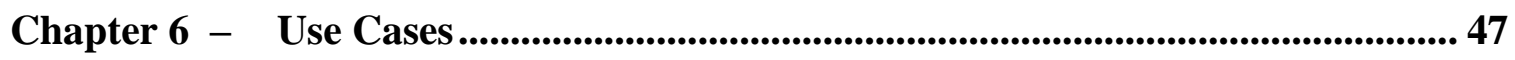

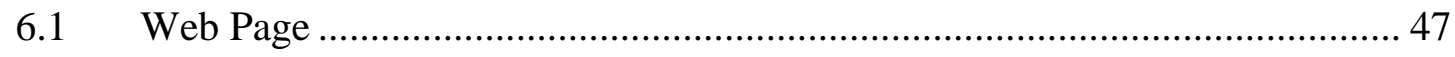

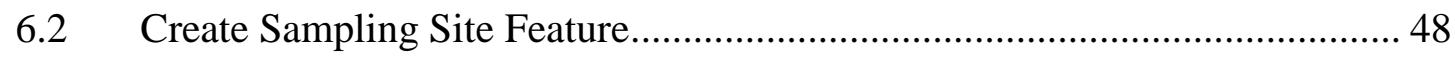

6.3 Create Measurement Type Feature ....................................................... 49

6.4 Create Sampling Value Feature ........................................................ 51

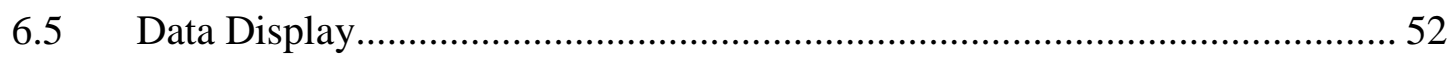

6.6 Viewing Records of a Selected Sampling Site Feature .............................. 53

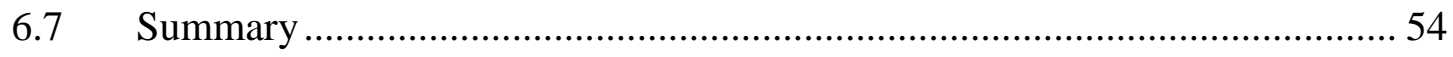

Chapter 7 - Conclusions and Future Work ......................................................... 55

Works Cited 59

Appendix A: HTML Code.......................................................................................................... 63

Appendix B: JavaScript Code ........................................................................................................ 67 
Appendix C: CSS Code 



\section{Table of Figures}

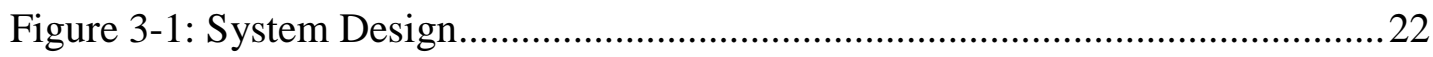

Figure 3-2: Project Plan ......................................................................................... 23

Figure 4-1: Data collection conceptual model .................................................26

Figure 4-2: Measurement table classification ................................................... 27

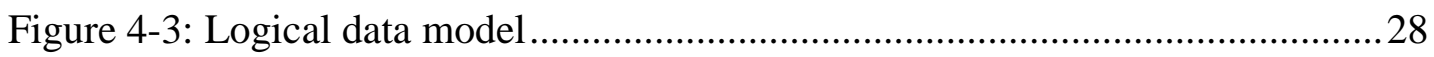

Figure 4-4: A map showing sampling sites published by U.S. Fish and Wildlife

Services in Washington State (U.S. Fish and Wildlife Service, Ecological Services,

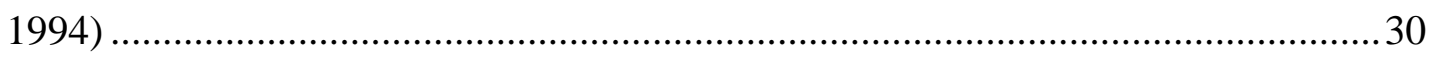

Figure 5-1: ArcGIS Online login through ArcMap .............................................. 34

Figure 5-2: Publish a Service wizard through ArcMap ....................................... 35

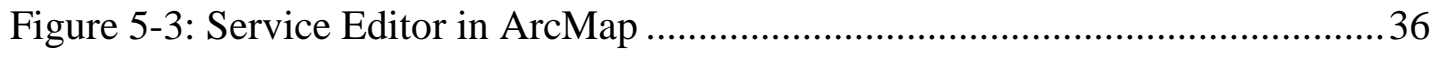

Figure 5-4: Web Application User Interface Design ........................................... 37

Figure 5-5: Popup Window showing attributes when user selects location on map to

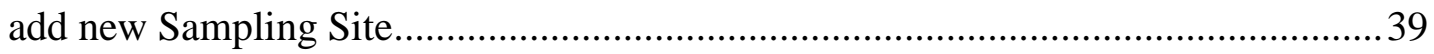

Figure 5-6: Workflow of Sampling Sites tool.................................................. 40

Figure 5-7: Workflow of new type of measurement tool ................................... 41

Figure 5-8: Workflow for creating the new sampling value tool............................42

Figure 5-9: Workflow for creating data display functionality .............................. 43

Figure 5-10: Data display example displaying all sampling values of distribution of Arsenic concentrations of eelgrass measurement types ..................................... 44

Figure 6-1: Snapshot of Eelgrass Research Application........................................ 47

Figure 6-2: New Sampling Site Feature Tool selected from Legend ...................... 49 
Figure 6-3: Editing Attributes of a Selected Sampling Site

Figure 6-4: New Measurement Type Feature Tool .............................................. 50

Figure 6-5: New Sampling Value Feature Tool ................................................ 52

Figure 6-6: Example of Data Displaying Lead Eelgrass Concentrations Sampled in

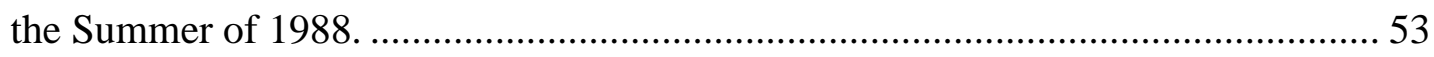

Figure 6-7: Snapshot of Sampling Values When Sampling Site is Selected ............ 54 


\section{List of Tables}

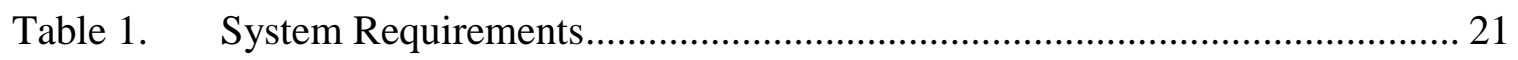





\section{List of Acronyms and Definitions}

$\begin{array}{ll}\text { API } & \text { Application Programming Interface } \\ \text { EWCP } & \text { Ethiopian Wolf Conservation Programme } \\ \text { HTML } & \text { HyperText Markup Language } \\ \text { HTTP } & \text { Hypertext Transfer Protocol } \\ \text { NOAA } & \text { National Oceanic and Atmospheric Administration } \\ \text { URL } & \text { Uniform Resource Locator } \\ \text { USGS } & \text { United States Geological Survey } \\ \text { VGI } & \text { Volunteered Geographic Information } \\ \text { YRITWC } & \text { Yukon River Inter-Tribal Watershed Council }\end{array}$





\section{Chapter 1 - Introduction}

This project focused on enabling the client to perform data management and spatial analysis using a Web GIS application; the client needed a database for her field data. These data included values and concentrations of several trace elements, chemical compounds, and nutrients that are harmful to eelgrass beds. Nutrient loading can cause stress on eelgrass plants due to the increased concentration of particles on the water's surface, resulting in insufficient sunlight for the plants. In addition to nutrient loading, coastal pollution is an important stressor of eelgrass. Multiple sources of coastal pollution have resulted in eelgrass decline. The client collected submarine groundwater discharge, sediment, and surface water samples for her research. The client also supplied a publication including similar eelgrass sample data. This publication included eelgrass and sediment samples. These data were compiled and used to populate the database for this project. An online application was used because of its ability to be shared and viewed by many people over the web and to deliver analysis results on the client side effectively.

\subsection{Client}

The client for this project was Dr. Rebecca Lyons, Professor of Chemistry at the University of Redlands. Her areas of expertise include water chemistry, water pollution, environmental modeling, and detection systems. Her responsibilities in this project were facilitating data collection, defining the project scope, identifying project requirements, and supporting analysis of these data. 


\subsection{Problem Statement}

Eelgrass, which is a major source of nutrients for coastal marine wildlife, was experiencing significant die-offs in San Juan County, Washington. Dr. Lyons needed a way to manage and organize collected data on the web. She was sharing data with colleagues using Microsoft Excel spreadsheets and consuming them in a web map on ArcGIS online, but this method was prone to data entry errors and did not have a database model implemented to maintain organization. Dr. Lyons and her collaborators were unable to increase public awareness of the die-offs with this method. Her web map did not reach the intended public audience and data were often edited and disorganized as a result of multiple undergraduate students performing analysis functions for class assignments.

\subsection{Proposed Solution}

The proposed solution to the client's problem was a Web GIS application to enable her to perform analyses, input data over the Internet, and organize these data in a database. The Web GIS application enabled the client to access the database with a Web browser, provided security for her data, and enabled her to increase public awareness of eelgrass die-offs with an online solution.

\subsubsection{Goals and Objectives}

The goals and objectives of this project included creating a Web GIS application that was accessible to multiple users in different locations and developing a database customized for the client.

The primary goal of this project was to develop a Web GIS application and a file geodatabase to avoid data entry errors and to organize data. The Web application was 
customized for the client and was developed by publishing Feature Services using ArcGIS for Server. One of the key requirements of the application was to serve as a repository for data both collected and documented in previous publications and those would be collected by the client in the future. These data were represented in tabular and spatial formats. A Feature Service was published that included sampling sites in a spatial table to enable the client to edit data and make changes to the database as more data are collected. The published Feature Service included a spatial table populated with fields named Site_Name, Site_ID, X_Coord, Y_Coord, Dates, and Status. These fields reflect information associated with each sample site included in the client's data. The Feature Service also included a table to define the types of sampling measurements with the following fields: Measurement_ID, Measurement_Name, and Units. These fields included information about measurements taken by the client in the field. The final table was the sampling values table, which included all the sample data values associated with each measurement. When the user of the application collected or obtained additional records to input to the system, the sampling values were stored in this table. It included Site_ID, Measurement_ID, Value, and Dates fields. The objective of the Feature Service was to enable the user to manage and maintain records in the database through the application.

An important objective was to develop the database to contain time-enabled data in order to create and visualize surfaces over a specific time from point features. To fulfill this objective a date field was created in the sampling values table and the sampling sites table. 
Another goal for the Web application was to enable the client to secure her database by requiring login credentials for users attempting to access the system. Users for this application included Dr. Rebecca Lyons and her collaborating scientists. Access to the application required a username and password with an ArcGIS Online global account.

\subsubsection{Scope}

The scope of this project included four main implementation components: designing a database model; publishing map services; designing and developing the Web GIS application; and editing data consumed by the application. The scope of this project included datasets of sampling sites located in the San Juan Archipelago. San Juan Island is one of the most populated in the group. The total number of islands varies depending on how they are counted. The islands are located about 80 miles north of Seattle in the northern reaches of Puget Sound. San Juan Island is only accessible by ferries, small boats, and by air. The San Juan archipelago's islands are located at junction of the Strait of Georgia and the Strait of Juan de Fuca between Vancouver Island, the Olympic Peninsula, and the continental mainland (Voltz, 2009). This project included only datasets with sampling sites located at San Juan Island, Padilla Bay, and Samish Bay. San Juan Island, Padilla Bay, and Samish Bay are located west of Bellingham, WA, which is a city located approximately 90 miles north of Seattle, WA. Padilla Bay is located in Skagit County, WA. Padilla Bay and San Juan Island were the primary study areas for this project.

A significant effort of this project was designing and implementing a database model that consistently represents the data presented by the client. This effort was the most significant because the client required management and organization of collected data on 
the Web. The client had struggled to organize her sample data and share with collaborators in a way that did not result in disorganization and corruption of the original data. With the proper design and implementation of a database, the client was able to maintain her original data and to share these data on the Web. The database was originally developed in ArcCatalog 10.2.2. Three Microsoft Excel tables were created and populated with the client's required data. The tables were sampling sites, types of measurement, and sampling values. The sampling sites table was populated with sampling site location coordinates in various locations near the shores of San Juan Island, Padilla Bay, and Samish Bay. The types of measurement table included information about each measurement done in the field, such as the name and type. The sampling values table stored the concentration values associated with each measurement. Start and end dates for each concentration were used.

The technical solution to the client's problem involved a Web GIS application which consumed data from a database developed for the client. Another component of the application was the ability for the client to edit data through the application. The database featured published services that supported editing from a user and the capability of restricting access to the client's data unless granted access with Esri global account credentials. Based on the client's requirements, undergraduate students with these credentials were able to view and even edit data. The client was using ArcGIS Desktop 10.2.2 software with a University of Redlands license which matched the environment of the machine used to develop the Web application. The responsibilities of the client included: data collection and delivery, frequent communication throughout the planning 
and development stages of the project life cycle, and supply specifications as the project developed.

\subsubsection{Methods}

This project was split into the following phases: Planning, Designing, Development/Testing, and Deployment. A File Geodatabase was developed in ArcCatalog 10.2.2 using data provided by the client. The sampling sites feature class was created along with two tables. The service was published using ArcGIS Server 10.2.2 and resides on the University of Redlands' server. The Web application was developed using ArcGIS API for JavaScript version 3.13. Aptana Studio 3 was the Integrated Development Environment used to develop the application. In order to create a tool that was user friendly, the client was involved in the designing process with frequent inperson meetings.

Data provided by the client were delivered in Microsoft Excel files. The other dataset was compiled from a published article by the U.S. Fish and Wildlife Service (1988). These data were manually scrubbed and loaded into the database. The data scrubbing and loading is discussed in detail in Section 4.5. Both datasets contained data that were collected to identify potential causes of nutrient loading and ultimately eelgrass decline in the study area. These data contain various trace elements, nutrients, and chemicals that have been identified by the client as major contributors to eelgrass die-offs. Nutrients include nitrogen, phosphorous, and orthophosphate. Trace elements included: lead, arsenic, beryllium, silver, aluminum, boron, barium, cadmium, chromium, copper, iron, mercury, magnesium, manganese, molybdenum, nickel, selenium, strontium, thallium, vanadium, and zinc. Other data included in the database were polycyclic aromatic 
hydrocarbons and aliphatic hydrocarbons. A file geodatabase was developed to manage these data and the Web application was used to display these data online.

\subsection{Audience}

The primary audience for this report was Dr. Rebecca Lyons and her collaborating scientists. The secondary audience was researchers involved with identifying potential causes of local die-offs and the general public who have an interest in eelgrass conservation. This report is generalized into non-technological language to communicate the GIS terminology to a broader audience including the client and her colleagues. This audience has limited knowledge of GIS or Web development. This report was intended to help the primary audience understand the objectives, methods, solution, and results of the project to gain a better understanding of how to use Web GIS as a solution to natural resource conservation research. The expected level of GIS knowledge for the audience is beginner or minimal.

\subsection{Overview of the Rest of This Report}

This report is comprised of seven chapters describing the project's implementation and execution. Chapter Two introduces a review of previous work related to eelgrass conservation, GIS and conservation, and spatial data sharing. Chapter Three details the system analysis and design of the project. Chapter Four describes data scrubbing and loading, database design, and conceptual and logical models of the database. Chapter Five outlines the steps taken to complete the project. Chapter Six offers a use case scenario for the developed application. Chapter Seven includes a summary, conclusions, and ideas for potential future work. 



\section{Chapter 2 - Background and Literature Review}

Eelgrass Zostera marina L. is a submerged sea grass that holds economic and ecological value and has been experiencing global die-offs. The decline in population is primarily due to excess nutrient pollution and the recurrence of wasting disease (Short, 1986, 1991). Eelgrass supports a complex food web and provides habitat for finfish and shellfish populations by virtue of its physical structure and primary production. The following chapter provides background information on eelgrass, discusses the various approaches to assess and monitor conservation of eelgrass beds, GIS and conservation projects, and examples of the value of spatial data sharing.

\subsection{GIS and Conservation}

GIS has been an important component of conservation efforts of many plants and animal species and habitat and biodiversity systems. The Smithsonian National Zoological Park (Smithsonian Institution, 2014) has led conservation projects in conjunction with various non-profits and other organizations. One example was the Asian Elephant Conservation Project. Asian elephants face extreme challenges and almost certain extinction in every place they exist. Only 30,000 to 50,000 remain in the wild across 13 Asian countries. Despite declining populations and increased threats, little information was available on accurate population figures, the extent of suitable lands for conservation, and the best potential lands for long-term conservation of Asian elephants.

The Asian Elephant Conservation Project used GIS technologies such as high-tech mapping using satellite imagery, GPS, and real-time tracking of wild elephant herds using satellite telemetry collars (Smithsonian Institution, 2014). These technologies were used to monitor the movements of Kandula, a lone adult male Asian elephant who 
occupied an isolated patch of forest outside the Yala National Park on the southeastern coast of Sri Lanka. Kandula and two other elephants were fitted with satellite collars in 2004 due to the collaborative efforts of Sri Lanka's Centre for Conservation Research, the Department of Wildlife Conservation, and the National Zoo. The collaboration's objective was to assess the feasibility of allowing elephants to forage on agricultural farm lands during the dry months (Smithsonian Institution, 2014). Kandula's collar yielded interesting results from one year of data in 2005. Initially, the entire year's data were plotted on a map. When the data were separated into wet and dry seasons, it became clear that Kandula spent more of the wet season, when farmers are planting and growing crops, in a forested area, away from the farm land. During the dry months, Kandula expanded his range to take advantage of available forage (Smithsonian Institution, 2014). These data provided critical information to wildlife managers to assess the movements of the elephants. By the use of GPS and GIS technologies, forage patterns, movement plots, and temporal trends enabled these managers to prevent conflicts and protect the welfare of humans and elephants.

Another species facing many threats to their survival was the Ethiopian wolf. With fewer than 450 wolves remaining in the mountainous regions of Ethiopia, rabies transmitted from domestic dogs was one of the primary causes of wolf fatalities (Gordon, 2010). The Ethiopian Wolf Conservation Programme (EWCP) and other organizations operated a rabies vaccination program that used GIS to target the best locations to vaccinate the wolves and dogs to prevent the spread of the virus (Gordon, 2010). The wolves lived in the Ethiopian highlands, which had become densely populated agricultural areas. Human development had surrounded the wolves' habitat, confining 
them to smaller areas and isolated from other wolf populations. Livestock overgrazed and trampled the natural Afro-alpine habitat and crops were becoming more viable, resulting in the loss of indigenous plant species. This led to loss of habitat for rodents, making food for the wolves scarce. The loss of habitat and prey coupled with rabies virus transmitted from local domestic dogs had resulted in rabies outbreaks in 1991-1992 and 2003-2004 (Gordon, 2010).

Dr. Jorgelina Marino, the EWCP's ecologist, began using ArcGIS software in 2005 to collect data from the organization's wolf monitoring team. Wolf and dog carcasses were recorded, as well as the number of wolves vaccinated at each trapping location. Dr. Marino and the EWCP mapped where vaccinations were concentrated from year to year and were able to efficiently plan where to target future vaccinations (Gordon, 2010).

\subsection{Eelgrass Conservation using Web GIS}

Eelgrass conservation efforts have included replanting areas experiencing local die-offs, studying water quality and identifying harmful compounds, and deploying conservation moorings. Planting eelgrass into the sediment of the ocean floor near the coast is one approach showing promising results. For several years, Jane Disney, director of Mount Desert Island Biological Laboratory had been refining her method of using biodegradable grids to introduce eelgrasses back into the sediment (Graves, 2015). Disney and her collaborators first tried using metal grids, weaving the eelgrass through a set of five holes. The Army Corps of Engineers had Disney and her team take the grids back due to concerns about leaving metal on the ocean floor. Disney then turned to wooden frames with biodegradable string but this proved to be too labor intensive and had to be planted at low tide. This was a problem because Disney and her team usually got only a couple of 
good tides each summer. They were only able to plant a small amount of grids at a time. Mary McInnes and William Carty approached the issues Disney was facing by collaborated over a few months to produce a ceramic disc with five holes, molded of soft clay, and fired in a pottery kiln. Carty's group at a university produced 70 discs and delivered them to Disney for trial use in the summer of 2015 (Graves, 2015). The plants are woven in and out of the holes. Volunteers and students stored the eelgrasses in tanks. These disks could be placed regardless of tide conditions. They were stored in tanks because time could be saved preparing them beforehand. Disney's eelgrass restoration project in Frenchman's Bay is estimated to wind down as the grass is recovering well.

NOAA collaborated with the Town of Tisbury, the Massachusetts Division of Marine Fisheries, the Environmental Protection Agency, and The Nature Conservancy to conserve eelgrass habitat near the Town of Tisbury by replacing traditional boat moorings with conservation moorings (NOAA, 2015). Traditional boat moorings used heavy chains and buoys to secure a vessel in one place in the water. Temporary anchors caused damage to the ocean floor by dragging and damaging eelgrass and other vegetation. New conservation moorings screwed into the seafloor and use flexible, floatable lines that do not drag across the floor and damage vegetation.

Environmental conservation and restoration reports have also been effective in eelgrass research conservation. Katharyn E. Boyer and Sandy Wyllie-Echeverria collaborated in 2010 in an effort to document eelgrass conservation and restoration efforts in San Francisco Bay, California (Wyllie-Echeverria \& Boyer, 2010). Their report stated that the earliest known studies of eelgrass in the Bay were done in the 1920s by William Setchell (Setchell, 1933), a botany professor at the University of California, 
Berkeley. It also said bay-wide surveys of eelgrass distribution were conducted in 1987 and 2003 (Wyllie-Echeverria \& Boyer, 2010). The 1987 survey reported an estimated total area of eelgrass throughout the central and southern regions of San Francisco Bay of 127.8 hectares (316 acres). This survey contrasted with its 2003 counterpart, reporting 1165.7 hectares (2880.5 acres). The 2003 findings included eight new sites and additional detected patches of eelgrass. The immense increase in total abundance and expansion of individual patches was thought to be due to improvements in mapping techniques. The 2003 survey utilized sidescan and single beam sonar with integrated GPS.

\subsection{Spatial Data Sharing}

GIS projects and applications are data driven. The implementation and analysis of data are fundamental components of an effective GIS. Sharing spatial data can be done in a number of ways. The most common is file sharing. Images, maps, and figures can be exchanged by exporting and email attachments. Methodologies can be documented and described in publications. The techniques and approaches used in an effective GIS can enable readers to repeat and amend these techniques in an attempt to find similar results. Results can also be shared through publications of various projects. Readers can attempt to find similar results using their own methodologies without repeating those of their sources. Each spatial data sharing technique varies in difficulty and effectiveness.

Often organizations collaborate to achieve goals, objectives, and results of projects driven by GIS technologies. One example was the major individual project completed by Gregg Breton in 2012. This project involved the Yukon River Inter-Tribal Watershed Council (YRITWC) and the USGS to monitor water quality within the Yukon River Watershed. The organizations were not visualizing water quality sites and were not 
sharing data effectively. The solution for this project was to develop a Web GIS application that the staff could use to view, query, edit, export, and share water quality sample data within the organization and collaborating researchers (Breton, 2012). Within the application, a data grid was developed and displayed for users to export data. When a user performed a query on a particular site, the data grid was available and showed all records associated with that site. An export option was developed that enabled users to download the data as a comma-separated value file. These files were prepared for export within the application, enabling YRITWC to share their findings with collaborating researchers.

Spatial data can be shared by exchanging files in various formats, but can also be shared through one common database. Enabling users to access a centralized database is powerful and effective for emergency management. All phases of emergency management depend on data from a variety of sources (Johnson, 2000). An emergency management GIS must have organized and logically displayed data to determine the size and scope of an emergency. During an emergency, the right data must be displayed at the right time in a logical manner in order for first responders to take action. Multiple government departments can be impacted by an emergency. By using GIS, these departments can share information through databases or maps. Without these capabilities, emergency workers are forced to contact specific department managers and gain access to their specific maps and data. GIS provides a centralized database to visually display critical information during an emergency (Johnson, 2000).

Spatial data can also be shared through Volunteered Geographic Information (VGI). An example of a project that used VGI to populate a database and share data of marine 
mammal identification was Managing Marine Mammal Observations Using a Volunteered Geographic Information Approach (King, 2012). This project used an ArcSDE database and a combination of Web and mobile GIS applications to enable whale watchers to submit observations to the database. Users of the application mainly consisted of citizens on commercial whale watching boats and those interested in contributing data to the application or involved in research of marine mammals. While users were on their commercial whale watching trips, they entered their observations through the mobile application using dialog boxes. When researchers finished the whale watching trips, they used the Web application to perform querying tools and download data as shapefiles.

Applications such as this that implement GIS can provide researchers with powerful tools to collect and organize data effectively and share those data with their intended stakeholders. Despite current VGI data quality issues such as species misidentification, GIS enables researchers to share spatial data and perform powerful analyses based on data contributed by the public.

The Washington State Department of Ecology created an online atlas featuring multiple data layers available for download (MacGregor, 2014). This atlas included shoreline photos, public beaches, shoreline biology, hydrography, spill response, shoreline modifications, and geomorphology. Using the atlas, researchers and stakeholders could download data as compressed files directly from the atlas to use for their own implementation. This was a powerful tool to increase public awareness for certain environmental and ecological issues. Many governmental organizations used the atlas as a tool, as well. With access to well-documented data from the atlas, organizations 
could implement them in their GIS to identify trends and patterns of certain natural resources and land management boundaries. Links were provided to print a map or shared as a map link.

\subsection{Summary}

By reviewing eelgrass conservation projects from prior publications and studying the rapid advancement of Web GIS technologies, several methods and variables were discovered that are important to understand when modeling eelgrass. Aerial photography, interpolation methods, linear regression methods, and Web GIS products enable organizations to communicate their information and reach their intended audience.

GIS has also been implemented in the conservation efforts of many species such as the Asian elephant and Ethiopian wolves. Examples of how the implementation of GIS technologies is an important approach to the survival of these endangered species were discussed.

In addition to species conservation, spatial data sharing was found to be highly effective in emergency management and ecological efforts. Whether a GIS exports spatial data of various file formats or provides a centralized database, sharing and communicating spatial data is a powerful tool.

Since around 2005, there has been a growing number of people using collaborative databases. This project's solution is a good implementation of 10-year-old technology. This approach requires maintenance. It was implemented for this project because the client wanted to leverage the power of Web GIS products to use a centralized database to display her research data to colleagues and the general public over the Web. Given the requirements in the next chapter, this project used this centralized database approach. The 
next section will describe the project requirements and system design that were integrated into a solution for the client. 


\section{Chapter 3 - Systems Analysis and Design}

In order to perform a thorough and effective system analysis and design, it is of utmost importance to plan. In order to create and execute that plan, one must visualize, analyze, and design the plan through identification of data, storage, and information products. Roger Tomlinson (2013), widely known as the father of GIS, said, "A GIS project is as good as its plan” (p. 15). In order to implement a plan for success, analysis and design of the system must be as thorough as possible. Every aspect of the problem must be visited. The project's data requirements, loading, replication, conversion, migration, digitizing, or scanning must be taken into account. The storage of these data must be designed. Multiple storage options are available including desktop, server, and cloud-based services. Maps, schematics, lists, 3D visualizations, animations, and online solutions are examples of information products that can prove vital to a project's success. This chapter details the system analysis and design and expands on the proposed solution discussed in Section 1.3. The problem that was solved for the client is discussed in Section 3.1. The requirements analysis is outlined in Section 3.2. Section 3.3 addresses the system design. The original project plan and its changes are discussed in Section 3.4.

\subsection{Problem Statement}

The primary issue the client faced that the raw observations of water chemistry data collected by the client and her colleagues were not being shared efficiently. The client needed a Web GIS application developed to better communicate her observations in order to increase public awareness of local area eelgrass die-offs. 


\subsection{Requirements Analysis}

All requirements were classified into functional and non-functional categories. The functional requirements describe what functions and capabilities the system must provide. They are determined by what the user wants the information product to be and to do. Non-functional requirements focused on how well the system must perform. These features typically support the functional requirements. For example, while the client and users of this application are not using the ArcGIS JavaScript API to make changes themselves, it was required for the Web GIS application to function. Additionally, the client requested that no software installation would be required to use the system.

The non-functional requirements addressed interfaces, usability, integration, performance, maintenance, and transitional aspects of the system. Both functional and non-functional requirements were determined after weekly in-person meetings with the client to learn what issues needed to be addressed. All of the functional and nonfunctional requirements identified are described in Table 1. 
Table 1. System Requirements

\begin{tabular}{|l|c|l|}
\hline System Requirement & $\begin{array}{l}\text { Functional/Non- } \\
\text { Functional }\end{array}$ & Description \\
\hline $\begin{array}{l}\text { Application Access through } \\
\text { login prompt }\end{array}$ & F & $\begin{array}{l}\text { The system shall prompt users for } \\
\text { credentials at initial login }\end{array}$ \\
\hline $\begin{array}{l}\text { Create new type of } \\
\text { measurement }\end{array}$ & F & $\begin{array}{l}\text { System shall enable users to create } \\
\text { new type of measurement }\end{array}$ \\
\hline Create new sampling site & F & $\begin{array}{l}\text { System shall enable users to create } \\
\text { new sampling site }\end{array}$ \\
\hline Create new sampling value & F & $\begin{array}{l}\text { System shall enable users to create } \\
\text { new sampling value }\end{array}$ \\
\hline $\begin{array}{l}\text { Sampling Values } \\
\text { Visualization }\end{array}$ & F & $\begin{array}{l}\text { The system shall generate heat map } \\
\text { surface upon selection of } \\
\text { measurement type }\end{array}$ \\
\hline ArcGIS JavaScript API 3.13 & NF & Client side development language \\
\hline ArcGIS Server & NF & $\begin{array}{l}\text { An ArcGIS Server used to host } \\
\text { client's data and application source } \\
\text { code }\end{array}$ \\
\hline User Manual & NF & $\begin{array}{l}\text { Simple step-by-step instruction to } \\
\text { help client and new users become } \\
\text { familiar with operating the system }\end{array}$ \\
\hline
\end{tabular}

\subsection{System Design}

Based on the client's requirements, a system was designed with two main components: a geodatabase and a Web GIS application. The geodatabase, server, application, and the other components of the system are shown in Figure 3-1. 


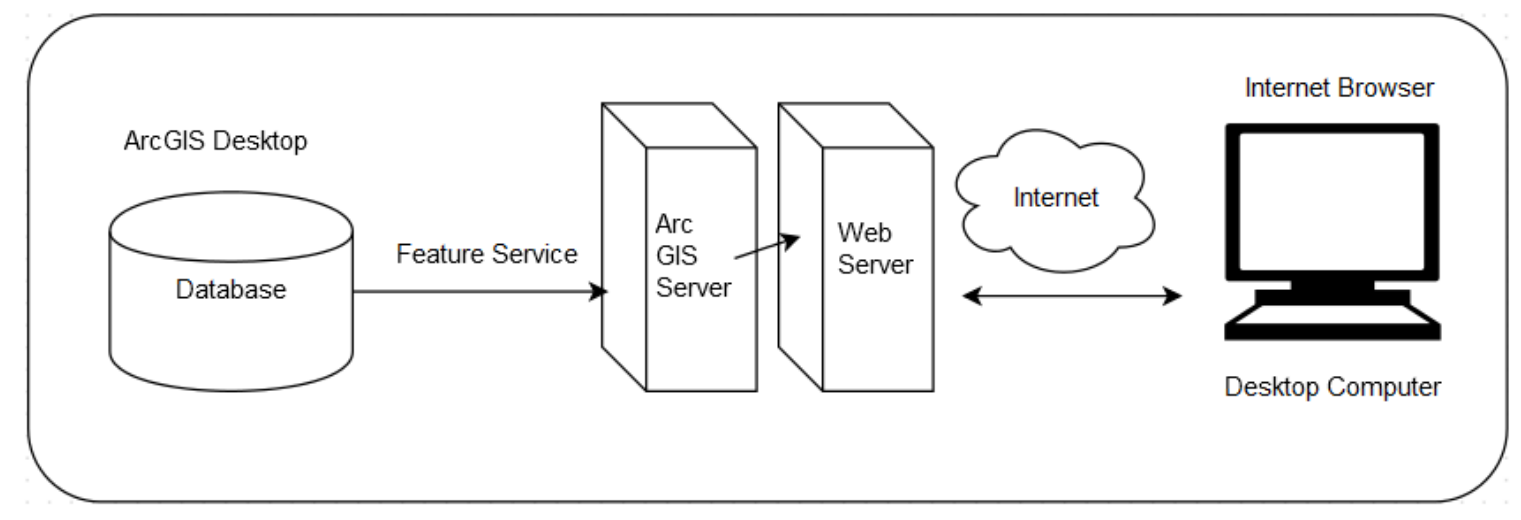

Figure 3-1: System Design

The key components of the system included a database with a point feature class and two tables. The first table contained types of measurements while the second table held sampling values. Each measurement is identified by a type and name of what was measured. The sampling values table has the raw observation values associated with each measurement. The database was designed to connect each measurement and observed concentration with the site where the sample was taken. This design limited redundancies and created the framework to enable the client to add new variables to the database with minimal amount of data entry. The point feature class contained point features indicating where samples were taken and location coordinates were documented. The database containing the sample sites, measurements, and raw observations was prepared for analysis. However, the client was not an experienced user of ArcGIS Desktop 10.2.2. In order to prevent the client from having to use ArcGIS Desktop extensively, the database needed to be accessed over the Internet. To accomplish this, a Feature Service was published. The feature service was accessed through a Web GIS application and enabled the client to consume and add records to the database through an easy to use Web browser interface rather than desktop software. The Web GIS application accessed the 
database through the Internet. The system was designed to be used on a desktop computer. The ArcGIS API for JavaScript version 3.13 was also used for development. Several functions were required for the Web application including query of the records within the database, adding records to the database, and rendering a heat map based on the Point Feature Class.

\subsection{Project Plan}

The planning phase is arguably the most important phase in a GIS project life cycle. The original project plan included five stages: initiation, planning, design, development, and deployment. Figure 3-2 details the stages of the original project plan and the timeline associated with each task within each stage. The project start, project duration, actual start, actual duration, and the periods tab indicate a 12-month project timeline. Month 1 was September and Month 12 was August.

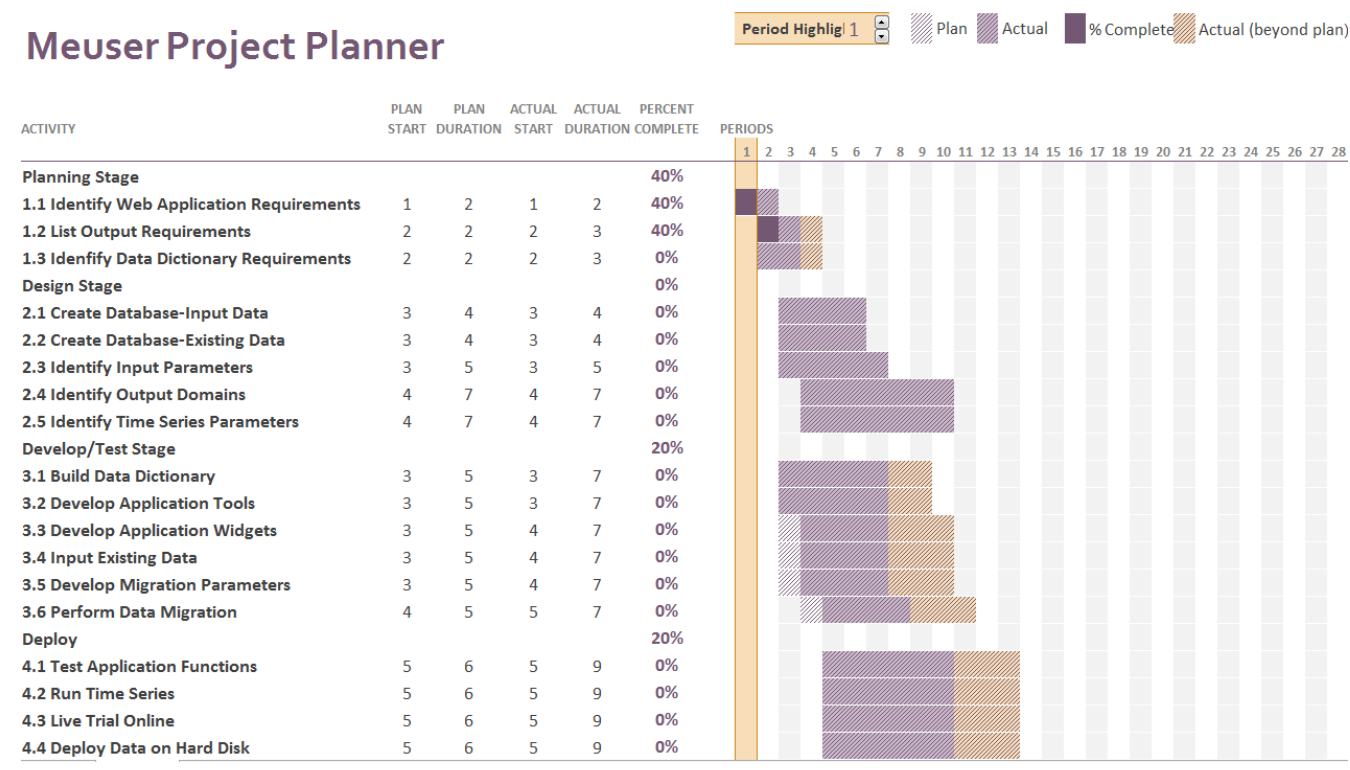

\section{Figure 3-2: Project Plan}

As reflected in Figure 3-2, the development and deployment stages of the project were planned to begin as early as January, 2015. This was to ensure the development 
stage did not get behind schedule. The planning stage was used to identify functional and non-functional requirements. These requirements were established through in-person meetings with the client. Meetings were held in person to build professional rapport and to ensure the client's vision was clearly articulated and understood.

The development and test stage began after the planning stage concluded. The system was developed to support the following functionalities: add records to the database, view and query records, and generate a heat map of records using sample site locations.

The deployment phase included testing all application functionalities through online trials, deploying the data on hard disk, and hosting the system on a GIS Server. The client did not have her own server, so the University of Redlands hosted the system.

\subsection{Summary}

This chapter introduced the challenges and issues related to the project's functional and non-functional requirements, system design, and original plan. Access to the application, heat map renderer, view and query capabilities, and the ability to edit records in the database were the functional requirements. These requirements, along with the system analysis and project plan, were a significant part of the system design. A Web GIS application was required. The client needed an application that had an interactive interface to perform analysis and display her collected data on the Web in order to increase public awareness of eelgrass die-offs. Chapter Four will discuss the database design that was introduced in Section 3.4. 


\section{Chapter 4 - Database Design}

GIS projects heavily rely on representation of geographic data to produce a variety of information products and deliverables. Database design is a crucial component to successful deployment. For this project, the database design was essential because edits to the database were to be made through the Web application. The system was designed to provide a solution for the client to perform these edits without installing new software. This method enables the client to add records through the Web application. The client required a Web browser on a desktop or laptop computer to use the system and perform these edits. The system functioned on a tablet or mobile device but was optimized for use on a desktop or laptop computer. The following chapter describes in detail the steps and processes that went into the database design. Topics include the conceptual and logical models, data sources, and the process that made the data available for use by the Web application. Section 4.1 introduces the conceptual data model with all of its components and how they interact with each other. Section 4.2 describes the logical model and why it was selected and implemented in this project. Section 4.3 includes data sources, and Section 4.4 discusses how these data were collected. Section 4.5 describes the rigorous process to ready and load the project's data into the database.

\subsection{Conceptual Data Model}

The process of analysis was important to study and validate the quality of data delivered by the client and to develop a conceptual model. The purpose of the conceptual model is to illustrate and communicate the client's problem and describe the entities of interest and their relationships. It is void of any particular database model. For the purpose of communicating raw concentration values of eelgrass research data, this project included a 
conceptual model based on locations of sampling sites and their measurements, as depicted in Figure 4-1. Each measurement or sample was measured by different methodologies. For this project, four measurement types were identified: submarine groundwater discharge, sediment, seawater, and eelgrass. Raw observations of these measurement types were added as attributes.

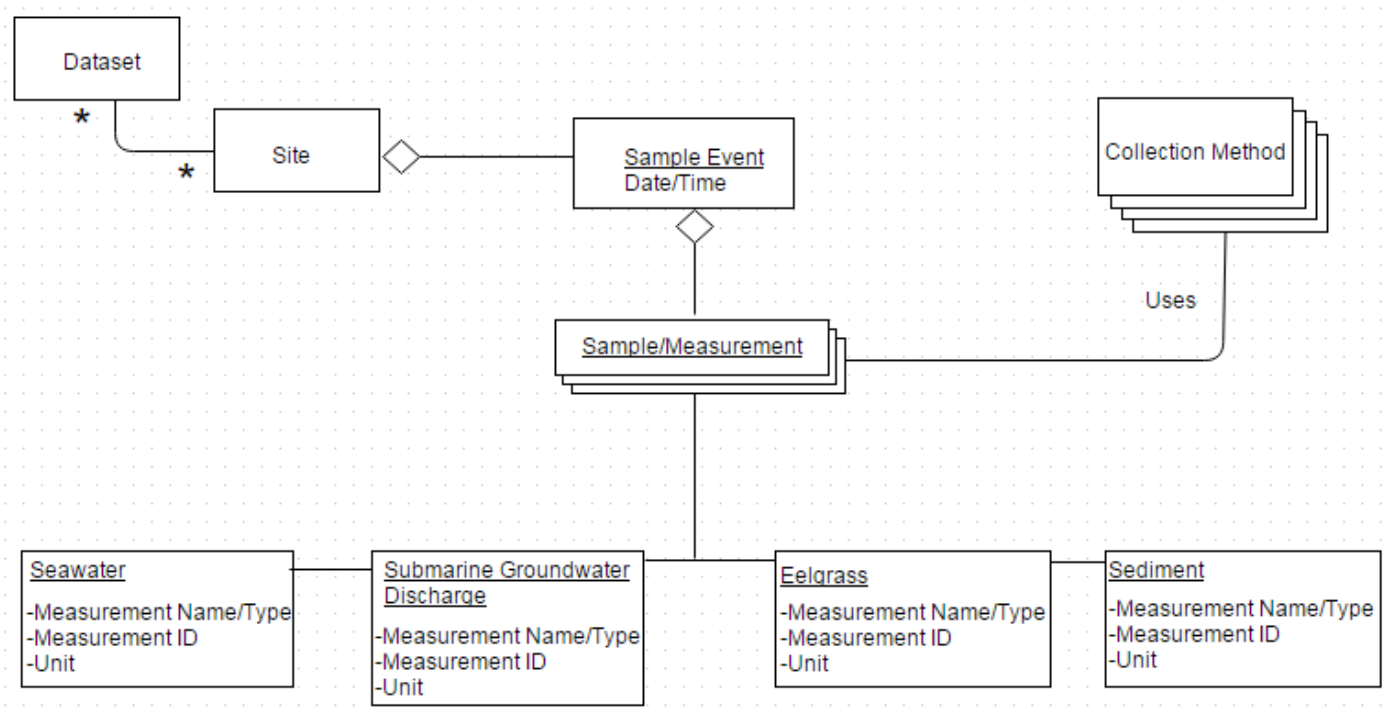

\section{Figure 4-1: Data collection conceptual model}

The data were implemented in such a way that allowed the user of the system to seamlessly add records to the database through the Web application. Data delivered to the client included locations of sites, units of measurement, different measurement names and types, and dates sites were visited. Each sample occurred at a specific date or range of dates. Each sample event uses a collection method. Individual samples are divided into four different measurement types with attribute data including concentration and date.

\subsection{Logical Data Model}

The logical data model for this project required a detailed analysis and review of the client's problem, objectives, and requirements. The purpose of the logical data model is 
to describe the feature classes and tables implemented for the database. Choices were to be made about how to represent each attribute and to implement a sound approach to model the client's data spatially. For this project, three tables were developed to interact with each other: the sampling sites, the types of measurements, and sampling values. The sample events from a sample site on the conceptual model were combined to form the sample sites feature class. The collection methods and all four of the measurement types were combined to form the measurement feature class. The data feature class contained sample site and measurement information.

The measurement table included various attributes including the measurement name and type. These were originally separated into two attributes but were combined to provide a more descriptive name for each measurement. The ID field for measurements were also easier to classify with this approach. Each measurement had an abbreviated name that matched with the name and type. Figure 4-2 illustrates an example of the measurement classification.

\begin{tabular}{|l|l|l|}
\hline Measurement_ID & Measurement_Name_Type & Unit \\
\hline N_SGD & Nitrogen_SubmarineGroundwaterDischarge & $\mathrm{mg} / \mathrm{L}$ \\
\hline N_SW & Nitrogen_Seawater & $\mathrm{mg} / \mathrm{L}$ \\
\hline P_SW & Phosphorous_Seawater & $\mathrm{mg} / \mathrm{L}$ \\
\hline P_SGD & Phosphorous_SumbarineGoundwaterDischarge & $\mathrm{mg} / \mathrm{L}$ \\
\hline Pb_SED & Lead_Sediment & $\mu \mathrm{g} / \mathrm{g}$ dry \\
\hline
\end{tabular}

\section{Figure 4-2: Measurement table classification}

Along with classification of measurements, decisions needed to be made about which other attributes were represented in the database. The database was developed to represent raw observations collected at sampling sites. Each sampling site includes an attribute to classify its status. Some sampling sites were visited by the client and 
university students while some were visited by other collaborating scientists. This method helped document more descriptive information about the sites.

The sampling values table contained each raw observation value. They were stored separately from the measurements and sites to maintain a one-to-many relationship. There would be more than one observation for each type of measurement. Also, individual measurements were performed at different sites. The sites and measurement tables followed the same one-to-many relationship, meaning each site allowed multiple measurements to be added. This method was developed to enable the user to add new attributes for each sample, measurement, and concentration to the database without risk of data entry errors and duplicating entries. The entire database is illustrated in Figure 43 , representing the logical data model.

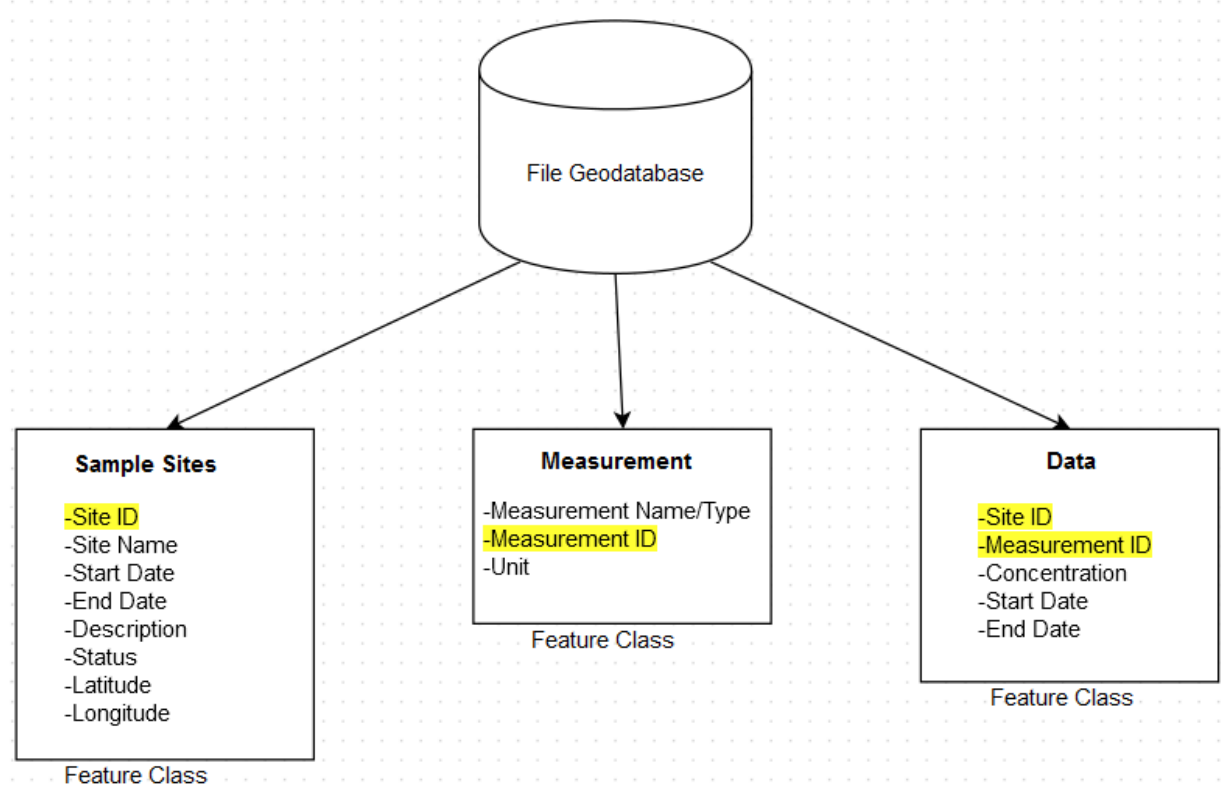

\section{Figure 4-3: Logical data model}

Three features were developed into a File Geodatabase. As described above, each feature class was separated by sites, measurements, and data observations. This method 
was effective at maintaining simplicity and representing the client's data spatially while limiting redundancies by implementing primary and foreign keys. For example, the sampling sites table links to the data table with the Site_ID field. When the user added a new data record, the site must be documented. The Measurement_ID field was a key developed in the measurement and data table. This approach helped avoid data redundancy.

\subsection{Data Sources}

The data for this project consisted of two datasets from two different sources. One data source was a publication from 1988 consisting of raw observations of trace elements and oil-related contaminants in sediment from the project study area (U.S. Fish and Wildlife Service, Ecological Services, 1994). It was published by the U.S. Fish and Wildlife Service's Washington State Office. This document was required for system implementation by the client. The other data source was the client, Dr. Rebecca Lyons. She collected data samples from multiple locations in the project area and delivered multiple Microsoft Excel spreadsheets. These data were unpublished private documents.

There were multiple data components for this project: an old map, raw observations contained in Microsoft Excel files, and concentration values derived from chemical analysis. The old map contained site locations where samples were collected and is illustrated in Figure 4.4. 


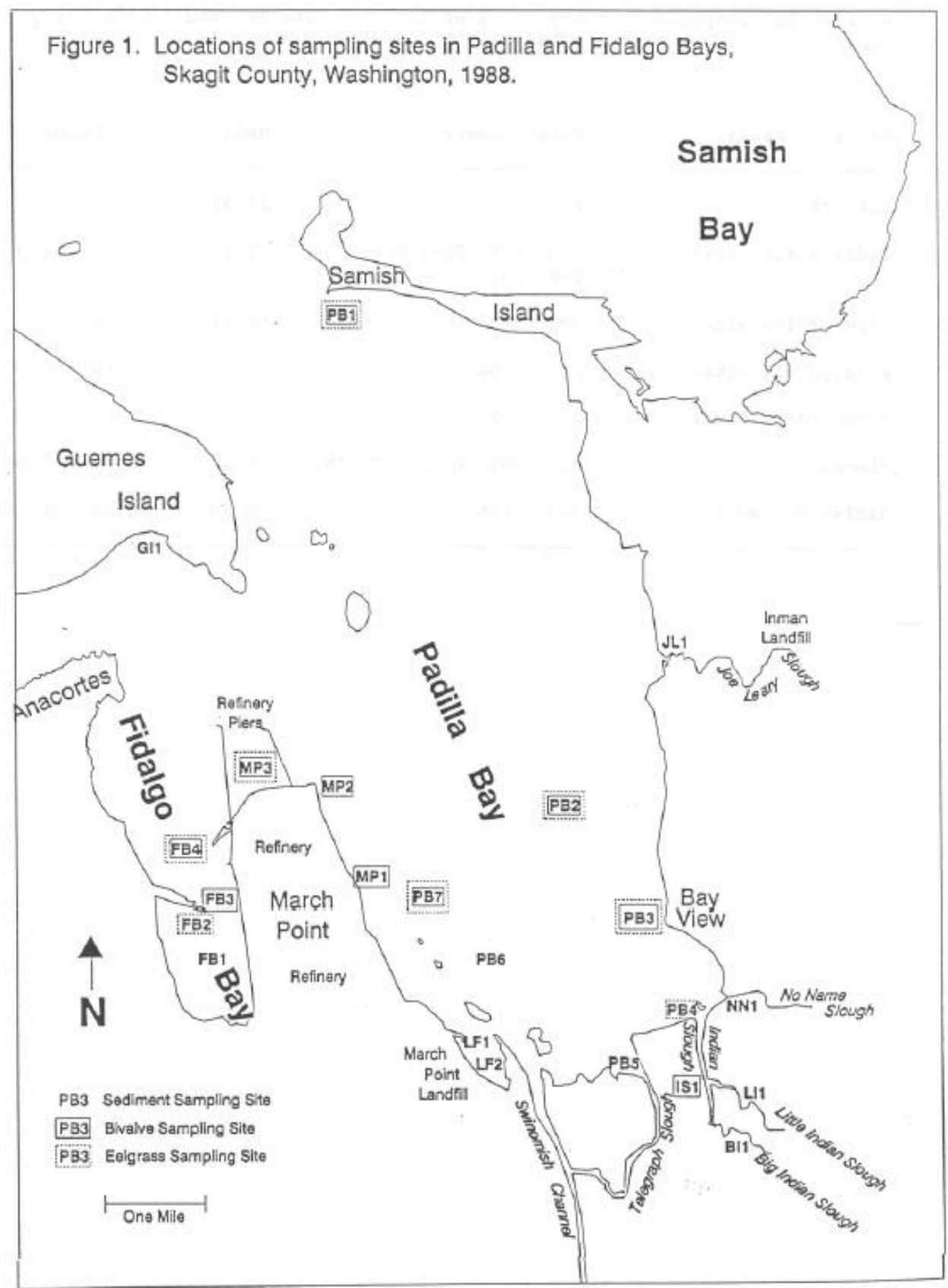

Figure 4-4: A map showing sampling sites published by U.S. Fish and Wildlife Services in Washington State (U.S. Fish and Wildlife Service, Ecological Services, 1994)

The raw observation values were included in the publication. These values were of multiple types of measurements. These included sediment and eelgrass types of samples. The U.S. Fish and Wildlife Service office in Olympia, Washington collected the samples. 
The sediment and eelgrass samples were analyzed for organochlorines, aliphatic hydrocarbons, and polycyclic aromatic hydrocarbons by Mississippi State Chemical Labratory at Mississippi State University. The sediment and eelgrass samples that were analyzed for trace elements were conducted by Environmental Trace Substances Research Center in Columbia, Missouri. The trace element concentrations were quantified by Inductively Coupled Plasma.

The client delivered her own raw concentration data in the form of Microsoft Excel files from sites sampled in the summer of 2014. These data reflected raw observations of various nutrients from water grab samples and analysis performed at the University of Redlands.

\subsection{Data Scrubbing and Loading}

The data required for this project required a significant effort of scrubbing and loading. The datasets were not prepared for direct use in this project upon delivery from the client. The data sampled by the client were delivered in multiple Microsoft Excel spreadsheets and were organized by individual nutrients and date sampled. These data were reorganized into three feature classes. All sample site locations from both data sources were combined into the sampling sites table. Multiple measurement types, names, and units were observed in the delivered data. Measurements were organized by an identification system that abbreviated the name and type of measurement to create one field. This field populated a feature class. The raw observation values were organized into a data table. These values were linked to the measurements table by the identification field. The result was a unique measurement linked to an individual observation. These 
measurements were linked to the sampling site they were taken at. The sites feature class shared the identifier field from the measurements table to ensure this connection.

\subsection{Summary}

This project required a significant effort to develop an effective database design. It required analysis of the data delivered by the client to develop a conceptual model to describe the database entities of interest and their relationships and a logical model to communicate the detailed components of the database and their connections. These models were developed through a process of data scrubbing and loading. As delivered, the data required preparation for implementation. This process of preparing the data was of particular importance to effectively communicate the database components to the client and the system's users. 


\section{Chapter 5 - Implementation}

Implementing a GIS solution to water quality research required a thorough analysis of system requirements and design, as well as a review of past projects that have used similar approaches. The implementation phase consisted of the development of a database and the Web GIS application delivered to the client. The database was developed to enable the client to seamlessly add nutrient and trace element records by providing fields for each measurement name, type, and value. The database contained field names that provided flexibility for the client to conduct new types of measurements in the future. This chapter discusses the methods used to create both the feature service published to the ArcGIS Online account and the Web GIS application developed in this project. Section 5.1 discusses the preparation and publication of the feature service. The development of the Web application is detailed in Section 5.2. The tools and functionalities of the Web application are discussed in Section 5.3.

\subsection{Publishing Feature Services}

The feature class for this project was used in the Web application and managed by ArcGIS Server and a Web Server. Considering how the client would interact with these layers and how they would be used in the Web application was important. In an effort to provide the client with an organized and simplified database, one feature service was published. This feature class contained a total of three layers: sampling sites, types of measurements, and sampling values of each measurement for various sites. All sampling site features were symbolized using simple marker symbols. Simple marker symbols enable the user to differentiate between the sampling sites. 
A feature service is a variant of a map service that enables Web editing. End users can add, edit, or delete features in the geodatabase remotely via a Web GIS client application (Fu \& Sun, 2011). The feature service published for this project had three layers, all of which the client could perform edits to. In addition, the client had an ArcGIS Online organizational account, a requirement to publish features services to ArcGIS Online, as they cannot be published to a free personal account. Publishing a service to an online account follows a similar set of instructions required to publish a service to an Arc Server account. A user must be logged in to their online account from within ArcMap before a service can be published. Figure 5-1 shows the login panel that is accessed through the file menu in ArcMap.

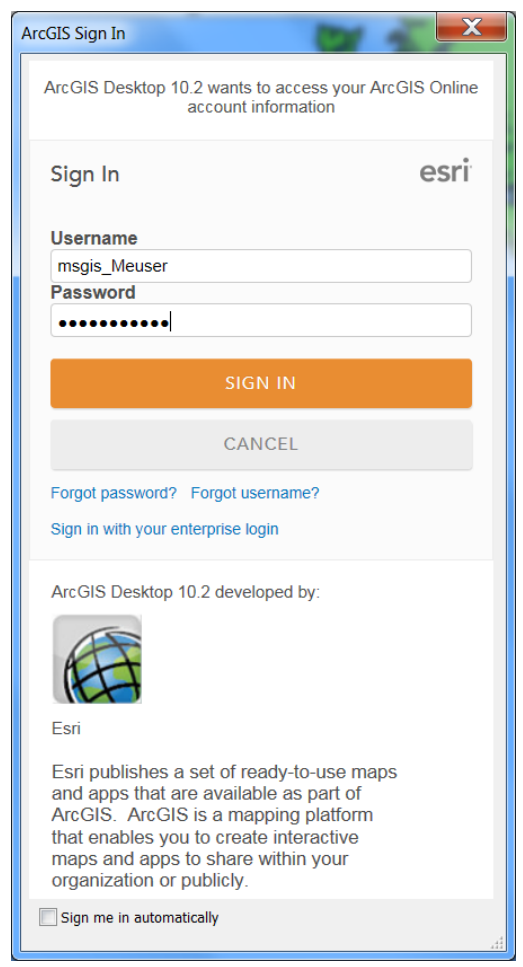

Figure 5-1: ArcGIS Online login through ArcMap 
Users can also add data using the ArcGIS Online content panel in ArcMap.

Published services and Web maps can be searched and viewed, allowing users to access details and add data to existing content.

When publishing a feature service to an online account, users select Publish a service from the Publish a Service wizard, shown in Figure 5-2. They can then submit a connection and name for the service.

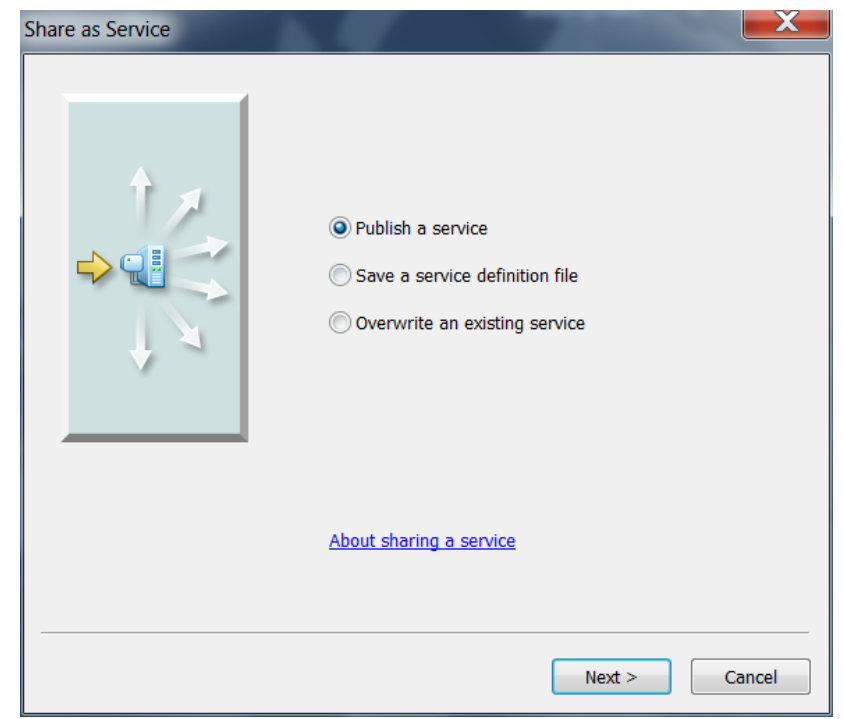

\section{Figure 5-2: Publish a Service wizard through ArcMap}

ArcGIS version 10.2.2 provides users with control over what editing operations are allowed for feature services. It includes a service editor with allowable operations such as create, delete, query, sync, and update. Figure 5-3 displays the service editor section, 
showing the configuration for allowable operations for the eelgrass research data feature service.

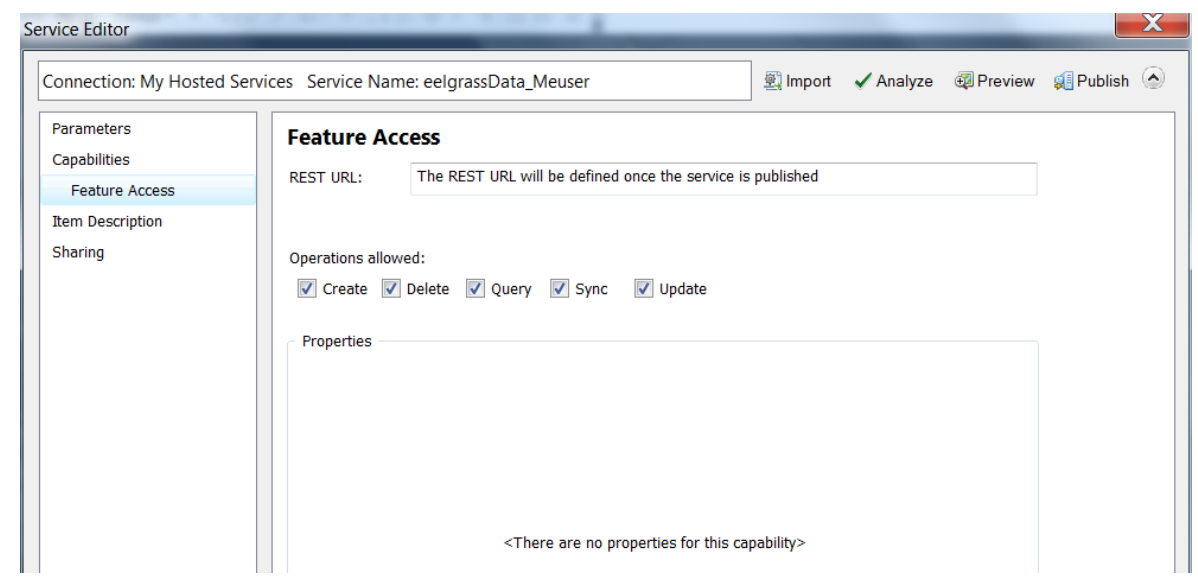

Figure 5-3: Service Editor in ArcMap

As geometries for the sample sites may change, create and delete options are available so the client can perform these operations for the measurement and data layers. To allow for easy querying within each layer, the user must make selections from drop down menus in the Web GIS application, which will be discussed further in section 6.2.

\subsection{Web Application Development}

The application developed in this project consisted of multiple tools: new sampling site, new type of measurement, new sampling value, and a data visualization tool. The application was written using HTML5, JavaScript, CSS3, and Dojo toolkit. The functionalities were developed using the ArcGIS API for JavaScript and the Dojo toolkit. The user interface was created using HTML5 with custom styling implemented with CSS3. The entire code development was completed in Aptana Studio 3 integrated development environment and the application was debugged using the Firebug add-on for Firefox Web browser and Google Chrome's developer tools for Chrome debugging. 
Aptana Studio 3, Firebug, and Chrome's developer tools are free open-source software packages.

Figure 5-4 provides an overview of the user interface. Using HTML5, a Web page was created. The title area of the Web application is located on the top of the page. The basemap toggle button is located on the top right corner while the left side of the page contains the user tools and selected site records. The rest of the page includes the overview map of the project area. The user can toggle between basemaps and use the other widgets in the map. Each yellow element in the interface design represent a widget's button.

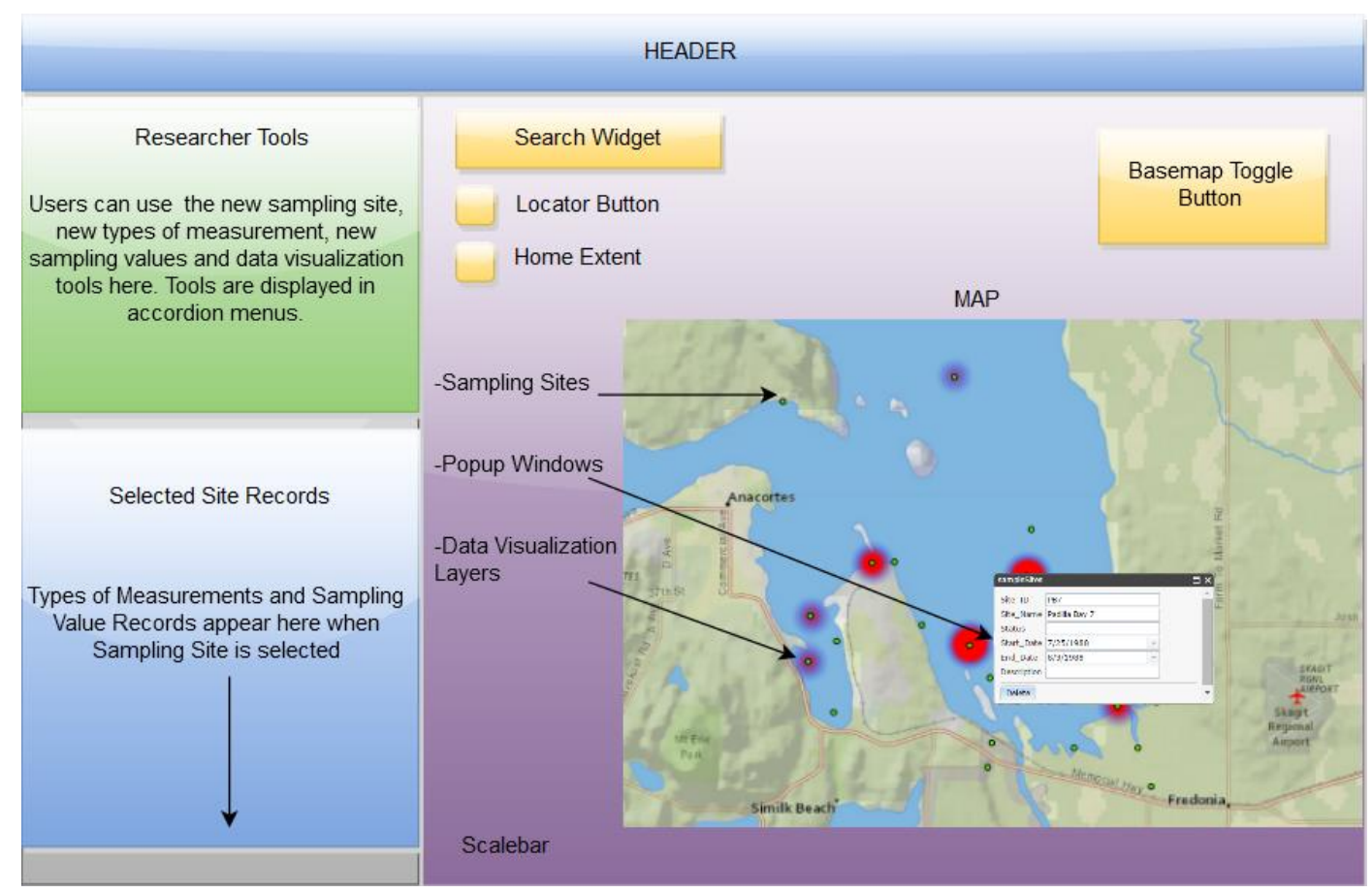

\section{Figure 5-4: Web Application User Interface Design}

Elements of a user interface such as the header, footer, and a main control panel are common to most Web applications. These elements only require development of unique element IDs and custom styling to make changes using HTML and CSS. The header 
element consists of a content pane with the title of the application, "Eelgrass Research Application." The div element named eMap was constructed to include multiple selection options inside of the map element, allowing the user to navigate throughout the project area and use the locator, home extent, search widget, and basemap toggle widgets. The Basemap toggle tool includes the satellite and national-geographic basemaps. The locator button was included because the system was designed for multiple users in different locations. The search widget was implemented to enable users to search for locations using addresses or latitude and longitude coordinates. The basemap toggle, home button, locator button, and search widget were classes used from the ArcGIS API for JavaScript.

\subsection{Tools and Functionalities}

The first tool implemented for the Web application enabled users to create a new Sampling Site. The tool contains a sampling sites point symbol. The symbol on the legend was developed using the editor class from the ArcGIS API for JavaScript. The user created a new sample site by selecting the icon in the legend and clicking a location on the map. The popup window was created to display Sampling Site attributes with an on-click event in JavaScript. A snapshot of a new sample site is shown in Figure 5-5. The template picker widget was used to display the popup windows with the on-click event. The popup window displays attributes that requires user inputs. The implementation of the Sampling Sites tool uses the following workflow: select point symbol in legend, select location on map, attach attributes, and apply edits. This workflow is illustrated in Figure 5-6. 


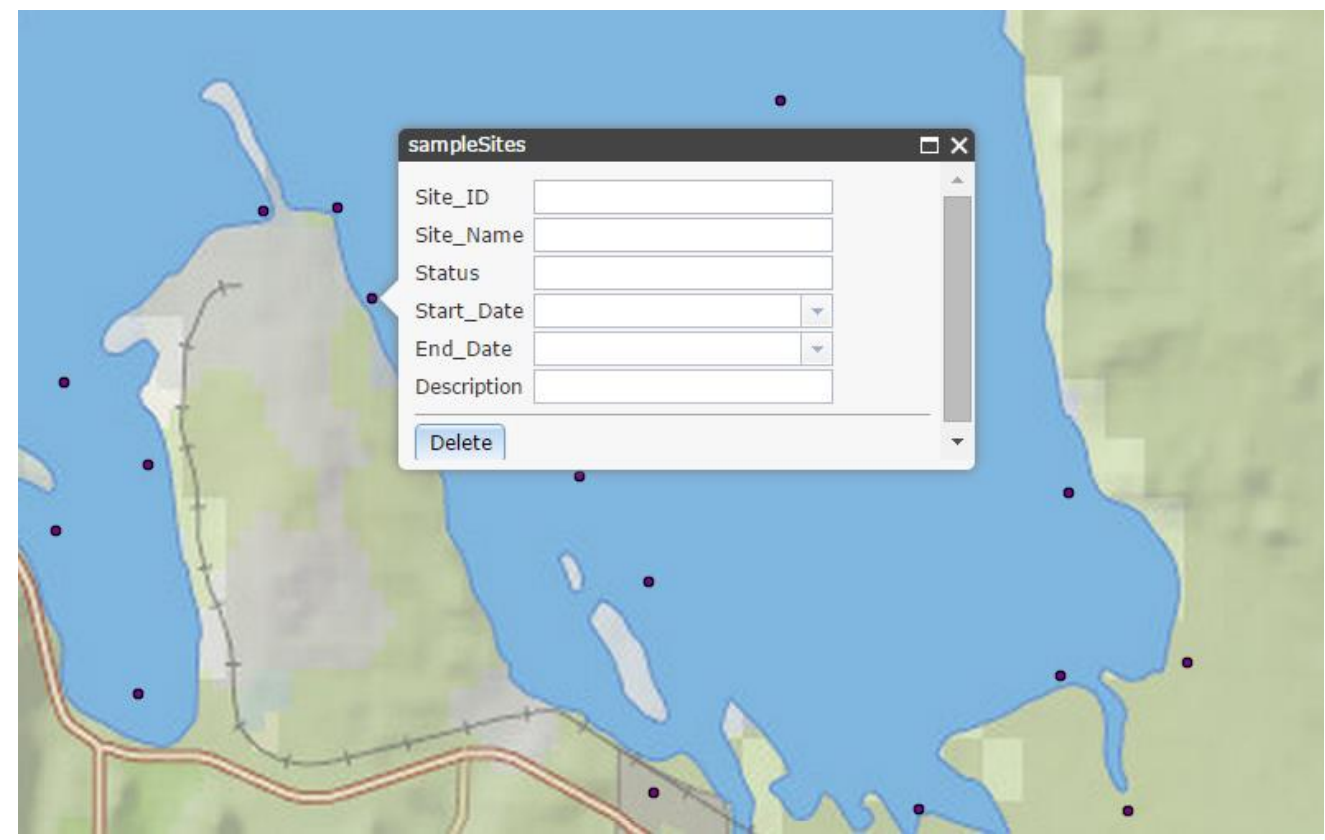

\section{Figure 5-5: Popup Window showing attributes when user selects location on map to add new Sampling Site}

In addition to creating new sampling sites, users can view records associated with each selected location. Two queries were executed when the user clicked a sampling site. The first queried through the sampling values layer, passing the sampling site attributes. The second query looped through the type of measurement table. An array was created and displayed using dojo.byId, which is defined in the dojo/dom module. The array was populated using the push method. Two widgets were developed to display the sampling site name above the queried types of measurements and sampling values of the selected sampling site. The results were displayed below the menu of user tools. If no records are associated with the selected site, the site name was displayed, but no records underneath it. 


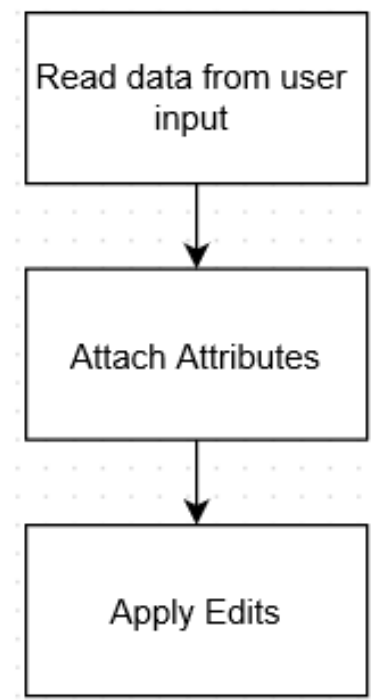

\section{Figure 5-6: Workflow of Sampling Sites tool}

The second tool enables users to create a new measurement type. It contained three text boxes for user inputs: Measurement ID, Measurement Name/Type, and Unit.

The workflow of creating the new measurement type tool followed these steps: read data from user input, add attributes to array with submit button, and apply edits. Figure 57 illustrates the new measurement type tool workflow. The data from the text boxes were added to an array and passed to the type of measurement table using a submit button, which uses the applyEdits method. This method allows users to add, update, and delete features in a feature layer. Once the user submits the values, a message function was called and generated a message window indicating the record was added successfully. If the function encountered an error, an error message was displayed indicating to the user that the record did not add successfully. 


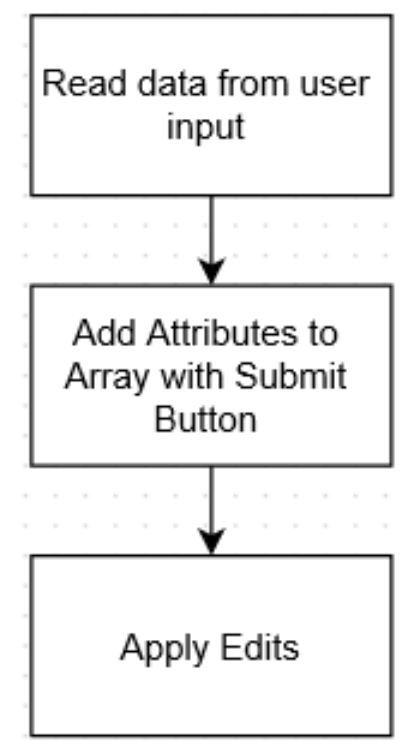

\section{Figure 5-7: Workflow of new type of measurement tool}

The third implemented tool enabled users to create a new sampling site value. It included both drop down menus and text boxes. This interface was developed by creating a table in HTML and aligning the elements to the left side of the pane for an organized structure using CSS. HTML was also used to develop the input text boxes and the select forms for the drop down menus. The user was required to select a sampling site and a type of measurement from the drop down menus. These menus were primarily developed using the QueryTask and Query classes from the ArcGIS API for JavaScript. The workflow of creating the drop down menus follows these steps: query types of measurement and sampling sites, add query results to array, and push array values to list of options. The list of options populated the drop down menu.

The workflow continued for reading the user inputs of the text boxes, following these steps: read data from user input, attach attributes, and apply edits using the Submit button. The text boxes required the following user inputs in text: sampling value, start date, and end date. The workflow for creating the new sampling value tool is shown in 
Figure 5-8. For users using Chrome browsers, the start and end date were selected from the date picker. The date picker was implemented by using date as the input type in HTML. For other browsers, the user was required to type the date manually. The system accepted both approaches from the different Web browsers.

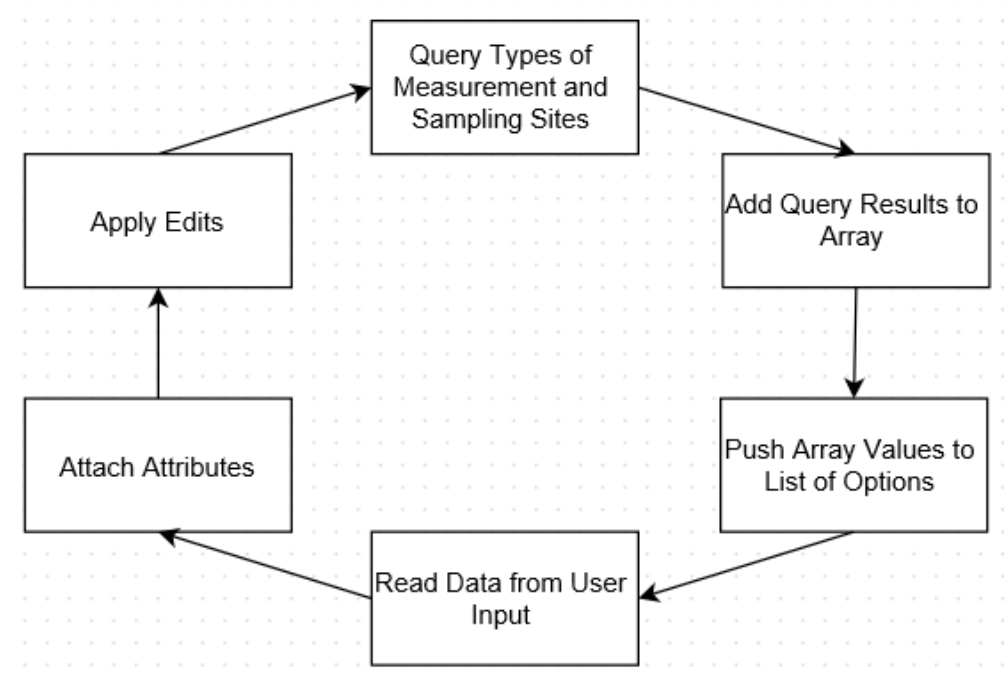

\section{Figure 5-8: Workflow for creating the new sampling value tool}

The final menu in the accordion container included the data display functionality.

The user was required to select a type of measurement. Similar to the new sampling value tool, a drop down menu was created for the user to select a type of measurement. A "from" date and "to" date input was developed using date input types in HTML. A query was developed so when executed, a function was called that finds sampling sites with records of the selected measurement type that fell within the selected time period. The QueryTask and Query classes were used, and an array of sampling values was created. A comma separated string of object IDs was created from the sampling values table. Another QueryTask and Query were executed where the Site_IDs were found in the string of object IDs. A count of the resulting sites was created. A dynamic layer was 
created using the FeatureLayer class. For each site counted, their attributes were selected and added to the new feature layer as graphics. The new layer was added to the map and the data display was implemented using the HeatmapRenderer class from the ArcGIS API for JavaScript based on the sampling value field. The layer included several properties: colors, blurRadius, maxPixelIntensity, minPixelIntensity, and field. The colors property used an array of CSS color strings. The blurRadius property indicates the number of pixels of the circle over which the majority of each points value is spread over (ESRI, 2015). A blur radius of 10 was implemented. The maxPixelIntensity of 10 was the number value assigned to the final color in the color ramp. The minPixelIntensity of 1 was the number value assigned to the initial color in the color ramp. The sampling values field was the string name of the attribute field used to weight the heatmap points. The resulting layer was dynamic and generated on the fly, as it does not save to the database at any time. The workflow of creating the data display is shown in Figure 5-9.

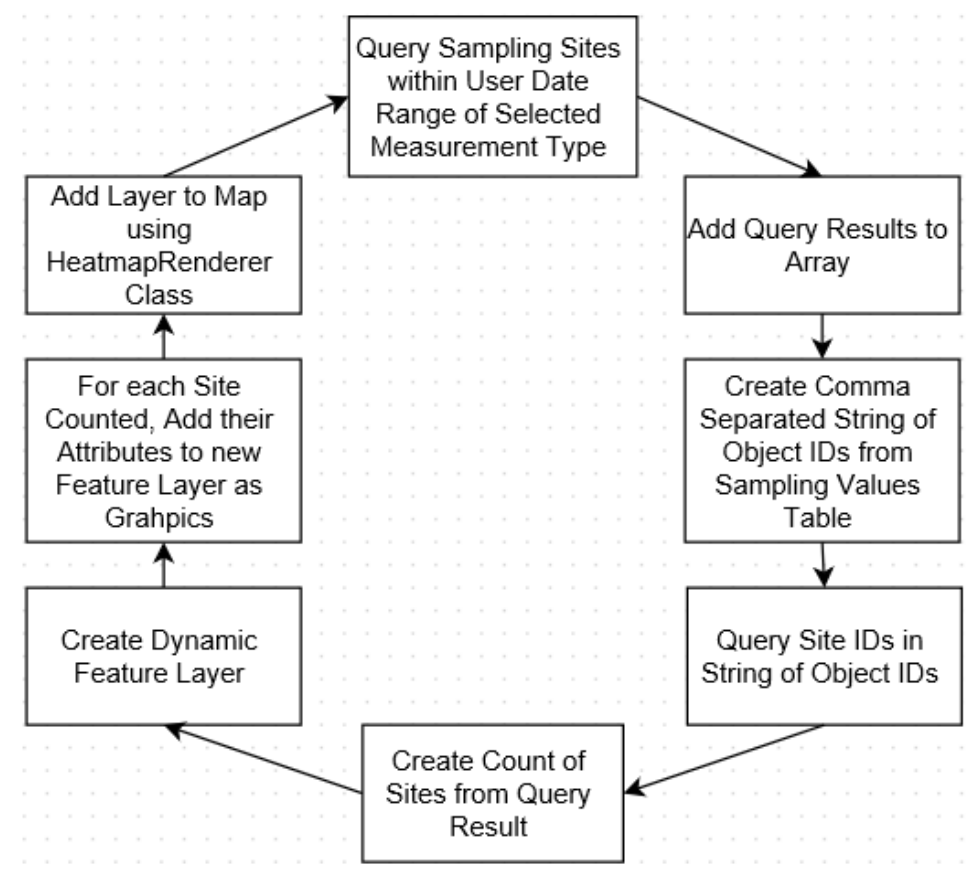

Figure 5-9: Workflow for creating data display functionality 
Similar to the new sampling value tool, two date selections were required. The dates created a time interval for the user to select all sampling values of the type of measurement within the selected time period. The date values were implemented in a query to identify all sampling values of the selected measurement type within the indicated time period. If the selected type of measurement does not have any associated sampling values, the layer was removed using the removeLayer method. A snapshot of a data display on the application interface is shown in Figure 5-10.

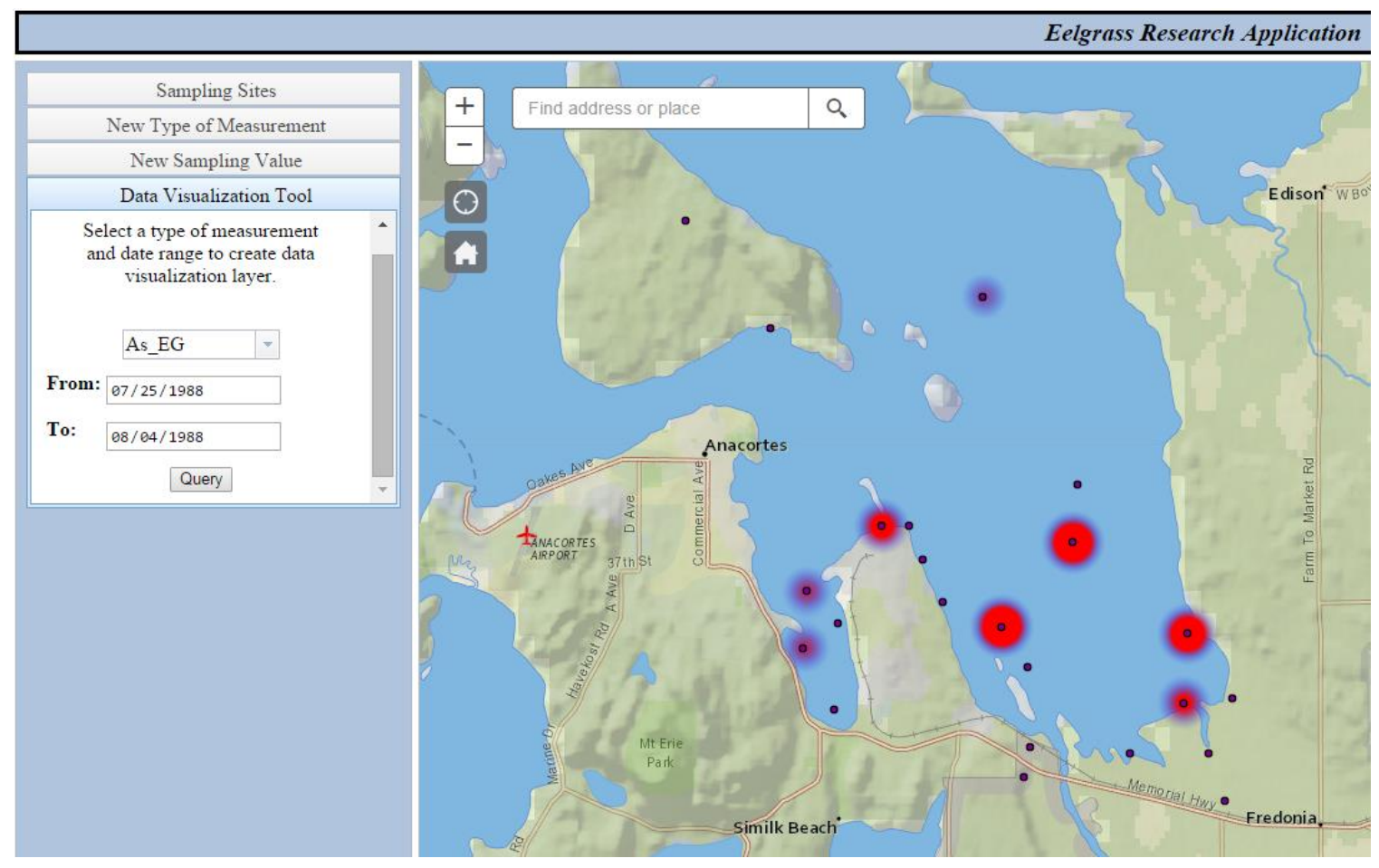

Figure 5-10: Data display example displaying all sampling values of distribution of Arsenic concentrations of eelgrass measurement types

\subsection{Summary}

Chapter 5 detailed the steps taken to prepare the feature service that was required for this project. It was published to an ArcGIS Online organizational account and managed by ArcGIS Server. A detailed discussion of the development of the Web GIS application followed. It began with using the ArcGIS API for JavaScript, Dojo, HTML5, and CSS3 
for development and finished with in-depth descriptions of the main functional tools in the application: user interface, adding new sampling sites, new types of measurements, new sampling values, and the data display. The source code for the Web application is in the Appendices. 



\section{Chapter 6 - Use Cases}

After researching, collecting, and creating datasets of eelgrass research from multiple sources, a Web GIS application was developed. Dr. Rebecca Lyons and her collaborating scientists were the primary users of the system. The application was developed for desktop use to serve as a centralized data repository. In this chapter, the use cases of the Web application are discussed.

\subsection{Web Page}

When the researcher opens the application, they are presented with the Web page, shown in Figure 6-1.

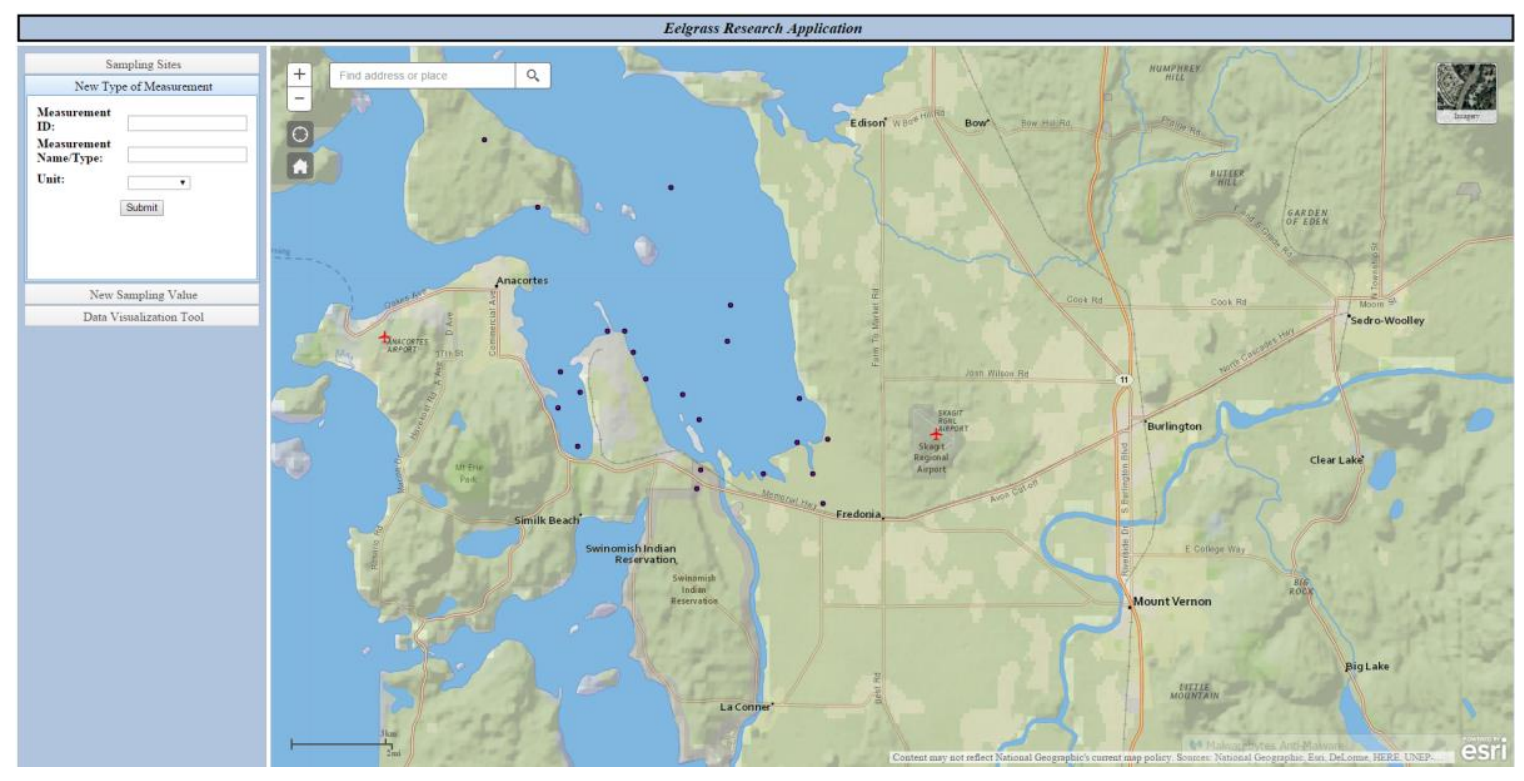

\section{Figure 6-1: Snapshot of Eelgrass Research Application}

The left side of the interface includes an accordion menu with various embedded custom tools. The researcher can use the new sampling sites, new type of measurement, new sampling value, and data visualization tools. To the right of the tool menu is the map. The map includes a locator button, home extent, zoom buttons, and a search widget 
on the upper left corner of the map section. The researcher can use the tools to center the map on their preferred extent. The upper right corner of the map contains a basemap toggle button, where the user selects between the national-geographic and satellite basemaps. The map contains sampling site locations. When the user selects a sampling location on the map, a popup window displays attributes for the selected site.

\subsection{Create Sampling Site Feature}

The primary use case of the developed application was to add records to the database over the Internet. Users of the application include researchers collecting data in the field and collaborators contributing data from previous publications. The following use case describes how users can use the application tools to create new sampling sites.

Multiple sampling values can be recorded at different times from the same site. In the case of visiting a new sampling site, one can be created in the application.

The researchers went out to the field to perform eelgrass research sampling and recorded the new sampling site they visited. To create a new sampling site, the researcher selected the sampling sites icon from the legend, shown in Figure 6-2.

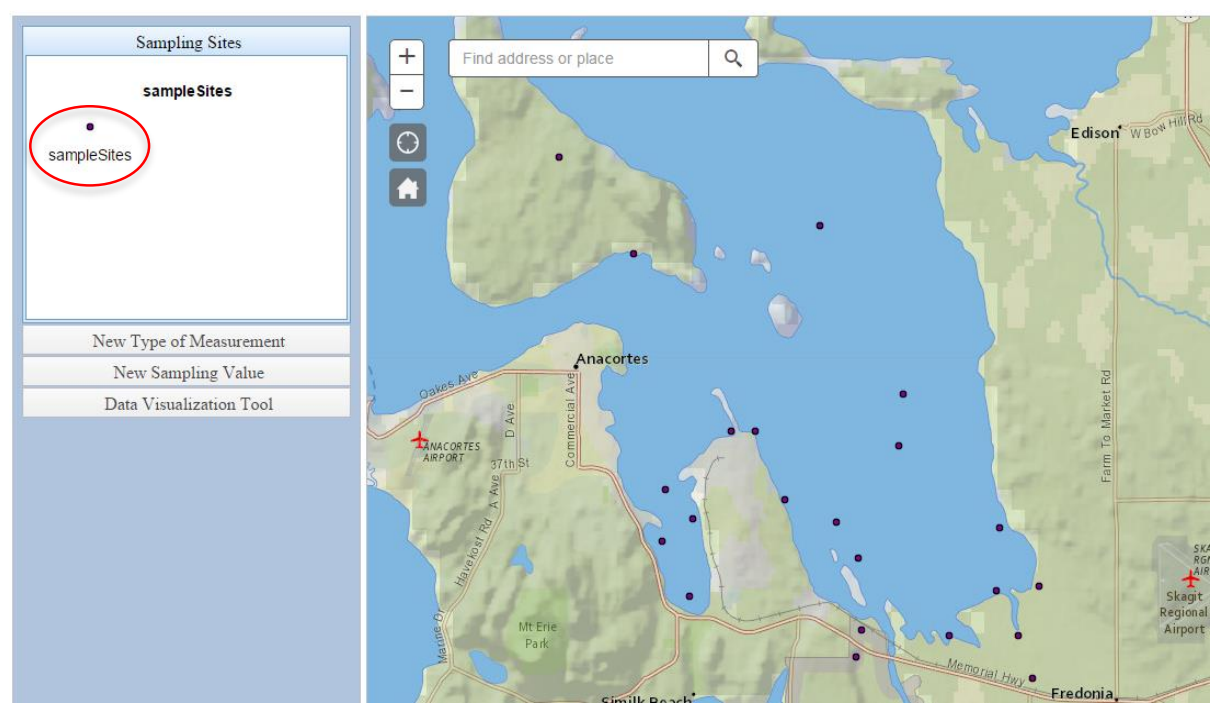




\section{Figure 6-2: New Sampling Site Feature Tool selected from Legend}

Once selected, the researcher simply selected a location by clicking on the map. With a click of the mouse, the location was recorded and the user was presented with a popup window, displaying the attributes to be filled in by the researcher. Sampling sites can be edited any time the user selects a site. Changes to the attributes are automatically saved to the server. An example of the sampling site popup is shown in Figure 6-3. Once the researcher completed filling in the attributes, the edits were applied, writing the record to the database. When the researcher realized he created a sampling site at the wrong location, he moved the point by clicking it, then clicking it again and dragging it to the updated location. The first mouse click changes the mouse cursor to a hand. When the hand was showing, the researcher clicked and dragged the point to move it.

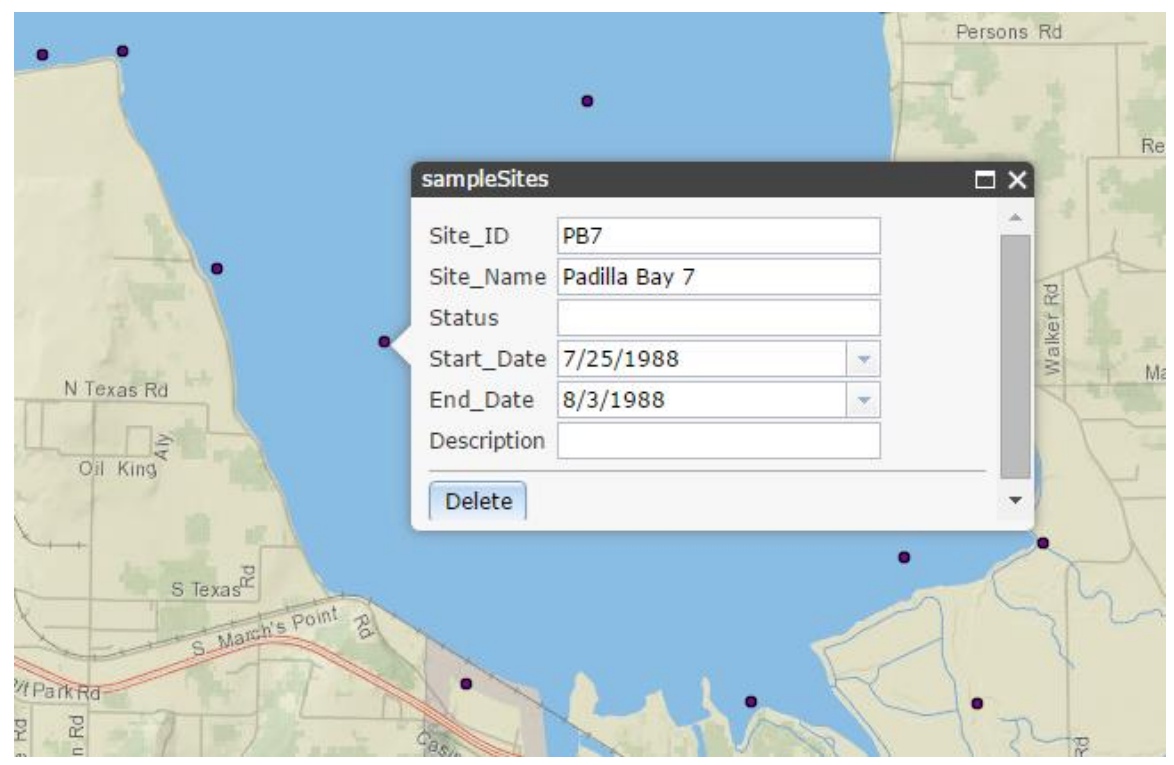

Figure 6-3: Editing Attributes of a Selected Sampling Site

\subsection{Create Measurement Type Feature}

Users will also be collecting data for new measurement types. Perhaps new instruments and methods will be used to record sampling values of different trace elements, nutrients, 
or other harmful compounds found in water samples. Using the application, researchers can submit new measurement types to the database.

Users collected samples for new measurements that do not exist in the database yet. The new measurement types must be recorded and organized. Using the new measurement type tool, the researcher can utilize the centralized database to store their new measurement findings.

To successfully submit a new measurement type to the database through the application, the user specified the name and type of measurement in the text box provided in the tool's interface. An eelgrass sample measuring nitrogen concentration was taken. To help organize the record, N_EG was created as the measurement ID. The unit of measurement was $\mathrm{mg} / \mathrm{L}$ and was selected from the drop down menu. The researcher clicked the submit button and all three values were added as a new record to the database. The new measurement type tool is shown in Figure 6-4. This process can be repeated for all new measurement types sampled in the field.
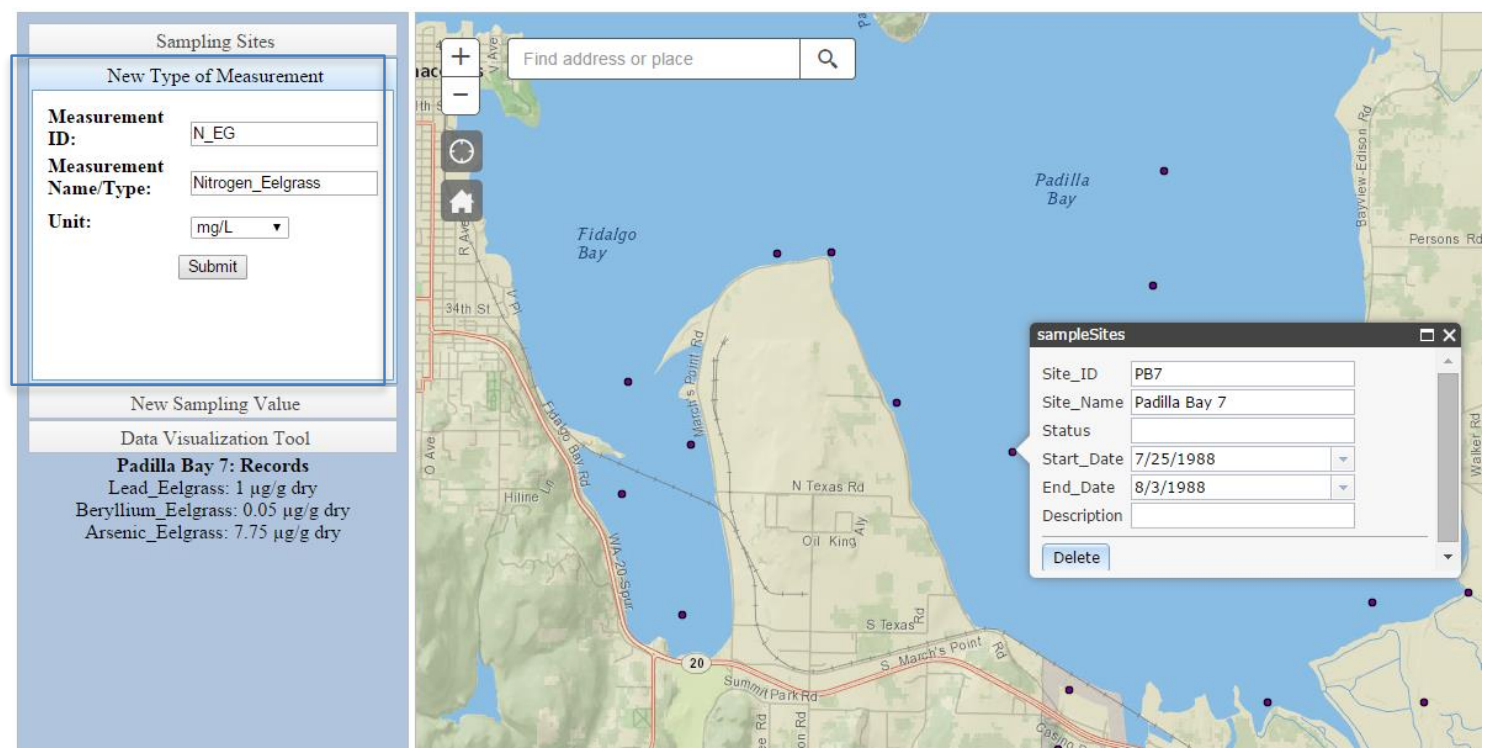

Figure 6-4: New Measurement Type Feature Tool 


\subsection{Create Sampling Value Feature}

A researcher visited a site and sampling was performed. The site was created in the application. The site and measurement type are created and the sampling values of the findings need to be added to the database. To do this, the sampling values tool must be used.

The researcher selected the site where the value was sampled. The site was Padilla Bay 7, so PB7 was selected. Next, the user selected the type of measurement. Since the Nitrogen_Eelgrass measurement type was previously added, it was available in the drop down menu of measurement types as N_EG. The sampling value of 0.025 was then retrieved from the text box provided. The start and end dates of when the value was taken were filled in. The sample was taken on July 18, 2014, and ended the sample on July 19. With the click of the submit button the record was added to the database. Start and end dates were provided because some sampling values were derived from weekly intervals, while other samples were completed on the same day. A snapshot of the new sampling value tool is shown in Figure 6-5. This process can be repeated for each sampling value collected in the field. A drop down menu was provided for sampling sites and measurement types to aid the user in submitting a sampling value to an existing site and measurement. A date picker was implemented for the start and end date attributes to enable the user to select dates without having to type them in manually. The date picker functions on Google Chrome browsers. Firefox and Internet Explorer browsers require the user to type the date as text. All date values in text submitted from any browser added the record to the database successfully. The start and end date attributes of the sampling 
site were provided to enable users to keep track of when the site was visited and were different attributes than the sampling value start and end dates.
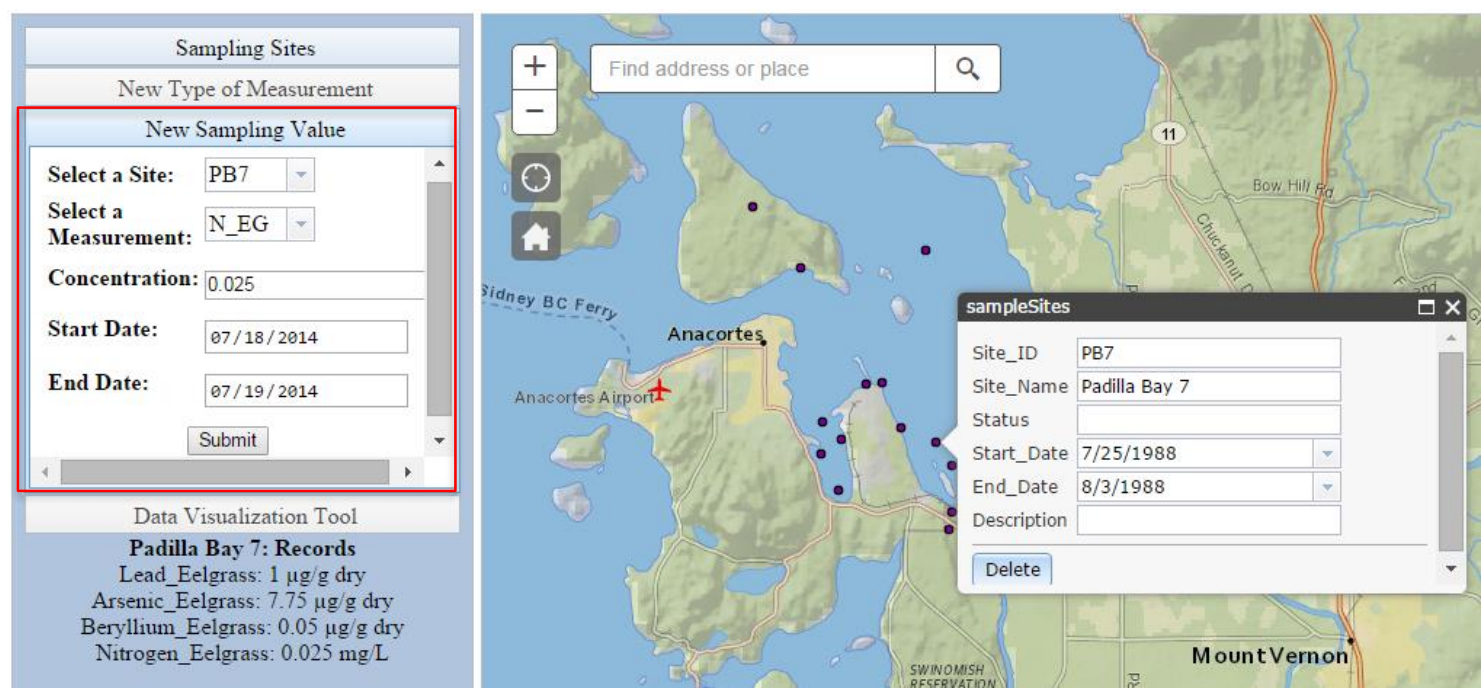

\section{Figure 6-5: New Sampling Value Feature Tool}

\subsection{Data Display}

Once the researcher created all newly visited sampling sites, submitted all sampling values, and created new measurement types, a way to visualize the values for each sampling site was needed. Using the data display, researchers and collaborators can do a quick evaluation of the distribution of sampling values on the fly.

To visualize a distribution, a measurement type was selected from a drop down menu. Then, a date range was specified by selecting two dates from the provided calendar tools. The tool performed a query which selected all concentrations within the selected date range. The query button was selected and the data visualization layer was generated. This dynamic layer was generated on the fly across all sampling sites containing sampling values of the selected type of measurement. The blur radius was based on the sampling values and displayed the highest values in red and the lowest in blue. An example of the visualization is shown in Figure 6-6. 

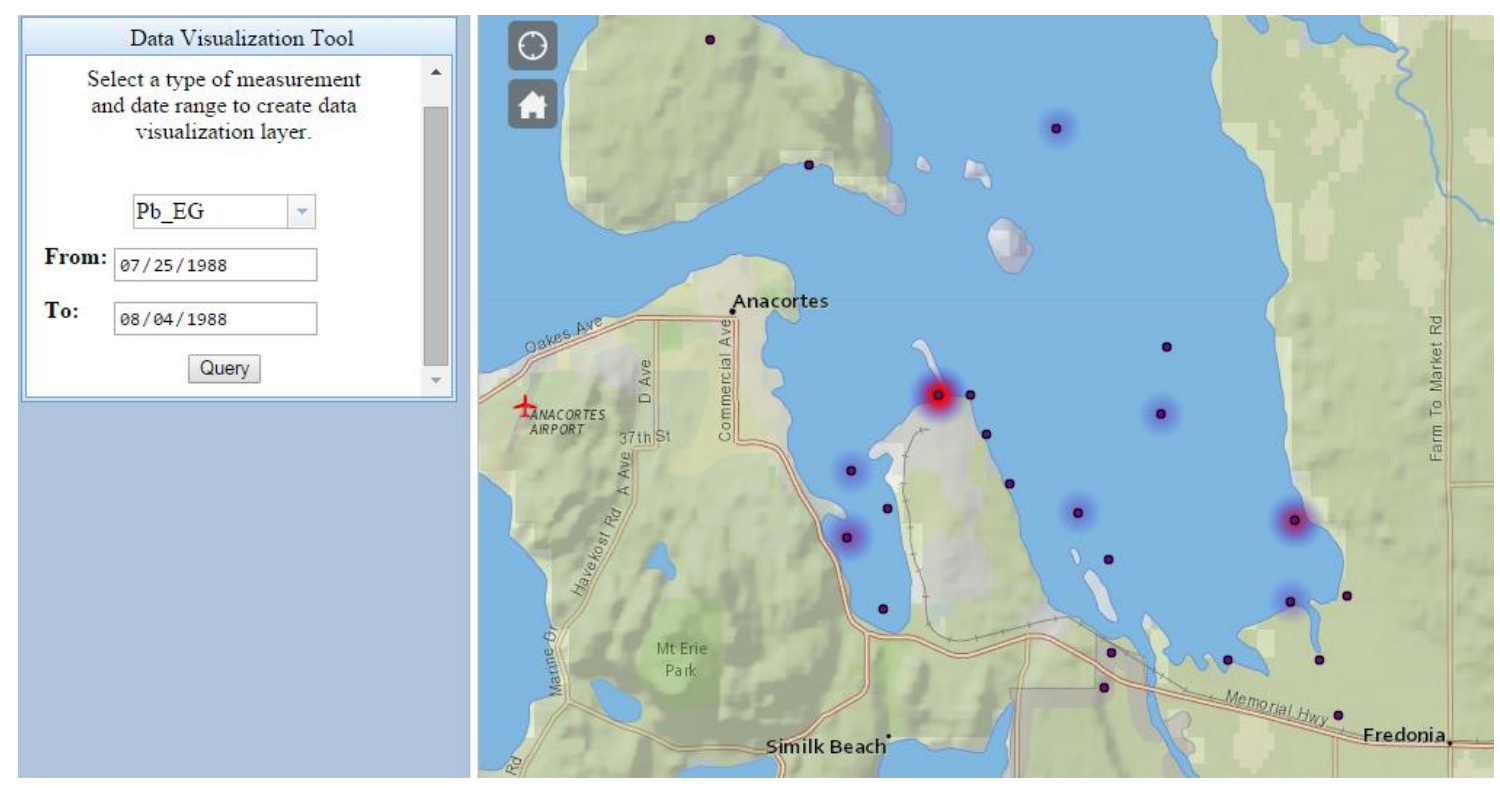

Figure 6-6: Example of Data Displaying Lead Eelgrass Concentrations Sampled in the Summer of 1988.

\subsection{Viewing Records of a Selected Sampling Site Feature}

A view of the sampling values that were taken at a particular site was needed. To do this, the sampling site must be selected. This function queries through the type of measurements and sampling values layers for all values with the selected site ID. For each of these records, the name and type of measurements are displayed with the corresponding sampling values and units of measurement. A snapshot of the displayed sampling values is shown in Figure 6-7. The newly added N_EG measurement type is added and the $0.025 \mathrm{mg} / \mathrm{L}$ sampling value is added to the database and displayed below the menu of user tools. This functionality provided the researcher with an organized list of all sampling values taken at a particular site. 

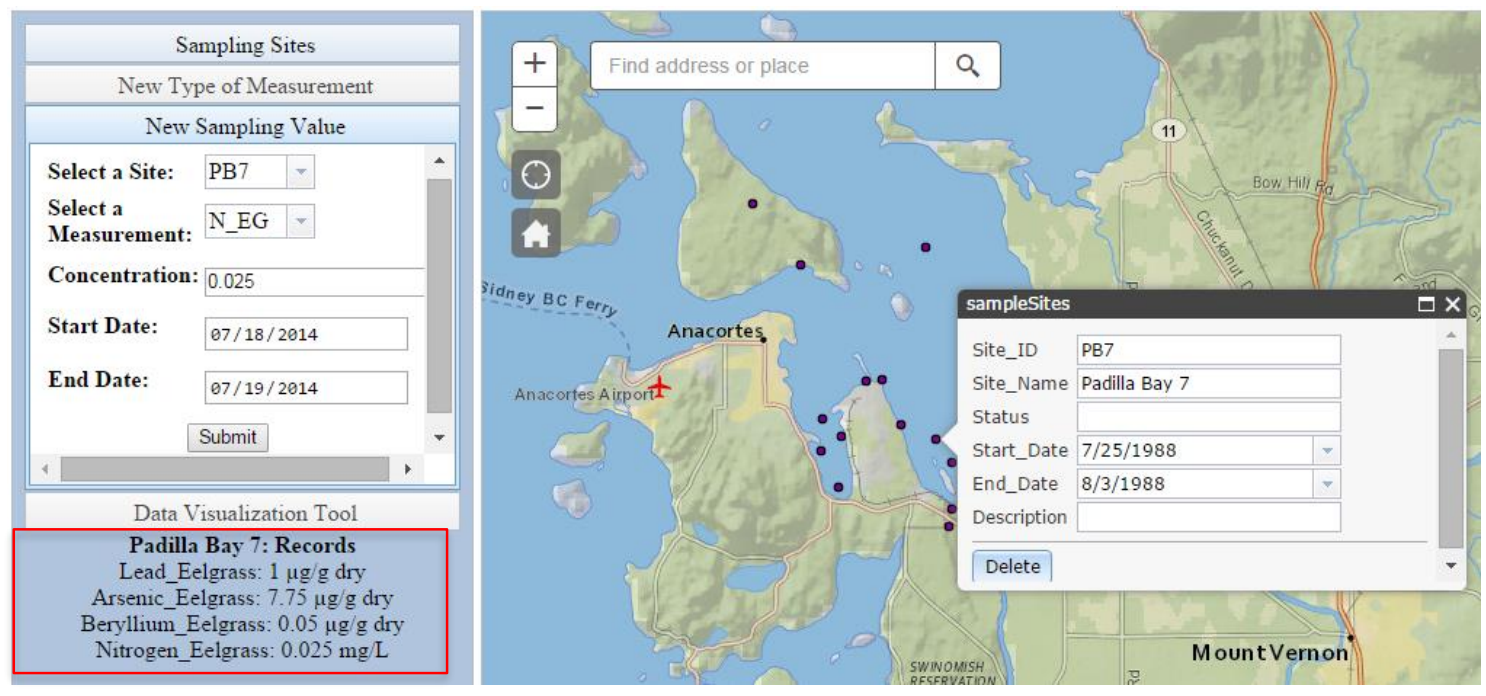

Figure 6-7: Snapshot of Sampling Values When Sampling Site is Selected

\subsection{Summary}

The goals of this project were to develop a centralized database management tool and a

Web application to consume and interact with the database through a Web browser. With

this application, the user was able to add sampling sites, types of measurements, and

sampling values to the database and do a quick evaluation of the distribution of nutrients

and trace elements across sample sites with the data display. The use cases of the

database and application were described showing how a researcher can use these tools. 


\section{Chapter 7 - Conclusions and Future Work}

The Eelgrass Research Application included a centralized database management tool and a user-friendly Web interface to perform an analysis of eelgrass research data. The application enabled the client to create and edit records in the database through a Web browser. With the delivery of the application, the client was able to collaborate with other scientists and eelgrass researchers in the San Juan Islands in Washington State. The project used private raw data collected by the client and a separate dataset compiled by the USGS. These data included Microsoft Excel spreadsheets and hard copy data tables, which were scrubbed and loaded into the database.

The project satisfied the client's functional and non-functional requirements. Functional requirements included creating records, generating a visual surface on sample sites, and prompting the user for credentials upon login. Non-functional requirements included the ability to edit over the Internet, create a User Manual to help train users, and publish a Feature Service using ArcGIS Server.

The client initiated this project to create the foundation of a data repository to support eelgrass research in the San Juan Islands. The project provided a prototype to prove how GIS can help Dr. Lyons and her collaborators manage and share their data efficiently. An extension of the work done to date could involve improving functionality of the application for the user. The first example is creating a query for values of units of measurement. The user is currently required to submit a selection of database options when using the new measurement tool when it would be more efficient to create a query that displays each type of unit of measurement found in the database. The work done to date does not populate the unit drop down menu with new attributes written to the 
database from the new measurement type tool. The query would enable the user to select any unit of measurement found in the database as an option.

An additional functionality improvement to the application would be to enable users to submit latitude and longitude coordinates to create and update the location of a new sampling site. Work to date supports the attribute editor from the ArcGIS API for JavaScript, enabling users to select the point feature in the legend and click a location on the map. The client records GPS readings to keep track of sampling sites and would benefit from creating sites as close to her readings as possible.

Another extension involves message status windows to help guide the user through using the tools of the application. For example, when the user submits a new record using any of the tools from the accordion container, the only confirmation is the record writing to the database. Furthermore, a window alert or a status message could be added to communicate with the user. The user would benefit from a notification alert that requires inputs from all entry fields. Examples include if start or end dates were missing, a measurement type already existed or a location was added on land as opposed to water. This functionality would require a check against a land feature class.

A potential issue with the application involves the start and end dates of records. Work to date supports a start date of a new sampling value to be after the end date. A check could be implemented to require users to submit a start date before the end date. Also, the data visualization tool requires users to create a time period by choosing two dates to query records from. If a sampling value contains a start date after the end date and is queried by the data visualization tool, a problem would likely surface. 
While the application provided the user with a heat map tool, a spatial interpolation has been received as a more powerful tool to provide the user with a more calculated and informative analysis. The heat map tool enables the user to do a quick evaluation of the distribution of nutrients and trace elements at sample locations, while an interpolation would enable Dr. Lyons to perform more in depth analysis and visualize her research data in different ways.

Another tool that could be coupled with an interpolation tool is a table viewer, in which the records in the database can be viewed and sorted. This would enable Dr. Lyons and her collaborators to view the records in the database directly through the Web application. The current work to date enables the user to view records for each site location when the site is clicked.

Further extension to this project that provides a MIP topic is an extension to the database design. As Dr. Lyons acquires more datasets and sources and conducts more research, the database will require more tables. This approach would provide Dr. Lyons with an organized structure of measurements that could be edited and queried through the application efficiently. 



\section{Works Cited}

Breton, G. H. (2012). Editing and Sharing Water Quality Data in Yukon Alaska (Master's Thesis). Redlands: University of Redlands.

Costello, C., \& Kenworthy, W. J. (2011). Twelve-year mapping and change analysis of eelgrass (Zostera marina) aerial abundance in Massachusetts (USA) identifies statewide declines. Estuaries and Coasts, 34, 232-242.

Dojo Foundation. (2015, July 16). BorderContainer. Retrieved from dojotoolkit.org: http://dojotoolkit.org/reference-guide/1.6/dijit/layout/BorderContainer.html

ESRI. (2015). ArcGIS API for JavaScript. Retrieved from https://developers.arcgis.com/javascript/jsapi/heatmaprenderer-amd.html

F., S., \& Burdick, D. (1996). Quantifying Eelgrass Habitat Loss in Relation to Housing Development and Nitrogen Loading in Waquoit Bay, Massachusetts . Estuaries, 19: 730-739.

Fu, P., \& Sun, J. (2011). Web GIS Principles and Application. Redlands: ESRI Press.

Gordon, H. C.-M. (2010, May 09). Conservation Group Uses GIS to Help Save Rare Ethiopian Wolves. Retrieved August 04, 2015, from http://www.esri.com/news/arcwatch/0510/feature.html\#acknowledge

Graves, L. (2015, August 02). Mount Desert Islander. Retrieved August 06, 2015, from Pottery kiln aids in eelgrass restoration: http://www.mdislander.com/featured/pottery-kiln-aids-in-eelgrass-restoration

Herning, J. (2013). A Web GIS Application for Oasis Ranch Management (Masters Thesis). Redlands: University of Redlands. 
Johnson, R. (2000). GIS Technology for Disasters and Emergency Management. Redlands: Environmental Systems Research Institute.

King, M. C. (2012). Managing Marine Mammal Observations Using a Volunteered Geographic Information Approach. University of Redlands, (Master's thesis, University of Redlands). Redlands: University of Redlands. Retrieved August 09, 2015, from http://inspire.redlands.edu/gis_gradproj/159

Klemas, V. E., Dobson, J. E., Ferguson, R. L., \& Haddad, K. E. (1993). A coastal land cover classification system for the NOAA Coastwatch Change Analysis Project. Journal of Coastal Research, 9: 862-872.

Kosgei, J. (2009). Implementing Web GIS for Monitoring Carbon Sequestration in Sustainable Agroforestry Projects (Master's Thesis). Redlands: University of Redlands.

Labriola, M., Tapper, J., \& Boles, M. (2012). Adobe Flex 4.5 Fundamentals: Training from the Source. Berkeley: Adobe Press.

MacGregor, B. (2014). Department of Ecology, State of Washington. Retrieved August 06, 2015, from Washington State Coastal Atlas Map: https://fortress.wa.gov/ecy/coastalatlas/tools/map.aspx?ZoomOptions=County|Sa n\%20Juan

NOAA, F. (2015, August 01). NOAA Habitat Conservation, National Marine Fisheries Service. Retrieved August 03, 2015, from NOAA Helps Eelgrass and Boaters Break Free of the Chains: http://www.habitat.noaa.gov/partners/successtories/maconservationmooring.html 
Precision Identification Biological Consultants. (2002). Methods for Mapping and Monitoring Eelgrass Habitat in British Columbia. Draft 4. British Columbia: Precision Identification.

Setchell, W. (1933). A Preliminary Survey of the Species of Zostera. Proceedings of the National Academy of Sciences of the United States of America 19.9, 810-817.

Shepherd, S. A., McComb, A. J., Bulthius, D. A., Neverauskas, V., Steffensen, D. A., \& West, R. (1989). Decline of seagrasses. In A. W. Larkum, A. J. McComb, \& S. A. Shepherd, Biology of Seagrasses: A Treatise on the Biology of Seagrasses with Special Reference to the Australian Region (pp. 346-387). Amsterdam: Elsevier.

Short, F. T., Burdick, D. M., Granger, S., \& Nixon, S. W. (1996). Long-term decline in eelgrass, Zostera marina L., linked to increased housing development. In J. Hus, R. C. Phillips, D. I. Walker, \& H. Kitkman, Seagrass Biology: Proceedings of an International Workshop (pp. 291-198). Nedlands, Western Australia: Sciences UWA.

Short, F. T., Jones, G. E., \& Burdick, D. M. (1991). Seagrass decline: Problems and Solutions. In H. S. Bolton, Coastal Wetlands, Proceedings of Coastal Zone '91 Conference (pp. 439-453). New York: American Society of Civil Engineers.

Short, F. T., Mathieson, A. C., \& Nelson, J. J. (1986). Recurrence of the eelgrass wasting disease at the border of New Hampshire and Maine, USA. Marine Ecology Progress Series, 29: 89-92.

Sites, A. (2010). Developing a Web Application for Citizen Volunteer Patrol in Redlands, California (Master's Thesis). Redlands: University of Redlands. 
Smithsonian Institution. (2014, June 18). Smithsonian National Zoological Park. Retrieved August 05, 2015, from Overview: Asian Elephany Conservation: https://nationalzoo.si.edu/SCBI/ConservationGIS/projects/asian_elephants/overvi ew.cfm

Tomlinson, R. (2013). Thinking About GIS, Fifth Edition. Redlands: Esri Press.

U.S. Fish and Wildlife Service, Ecological Services. (1994). Trace Elements and OilRelated Contaminants in Sediment, Bivalves, and Eelgrass from Padilla and Fidalgo Bays, Skagit County, Washington, 1988. Olympia: Washington State Office.

Voltz, D. (2009, February 26). San Juan Archipelago. Retrieved August 06, 2015, from New World Encyclopedia: http://www.newworldencyclopedia.org/p/index.php?title=San_Juan_Archipelago \&oldid $=937217$

Wyllie-Echeverria, S., \& Boyer, K. (2010). Eelgrass Conservation and Restoration in San Francisco Bay: Opportunities and Constraints. San Francisco: Final Report for the San Francisco Bay Subtidal Habitat Goals Project. 


\section{Appendix A: HTML Code}

\section{HTML Code for Application}

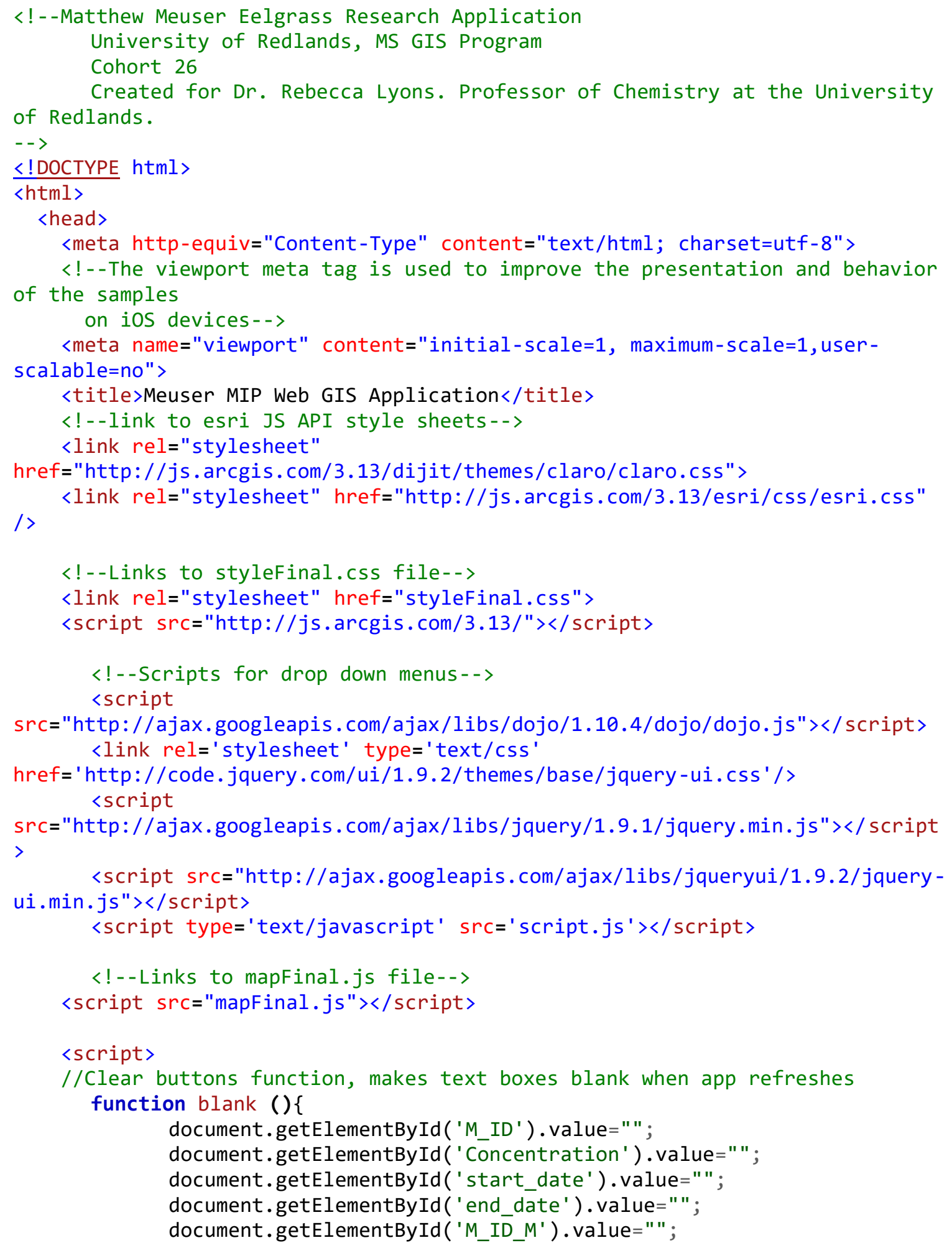




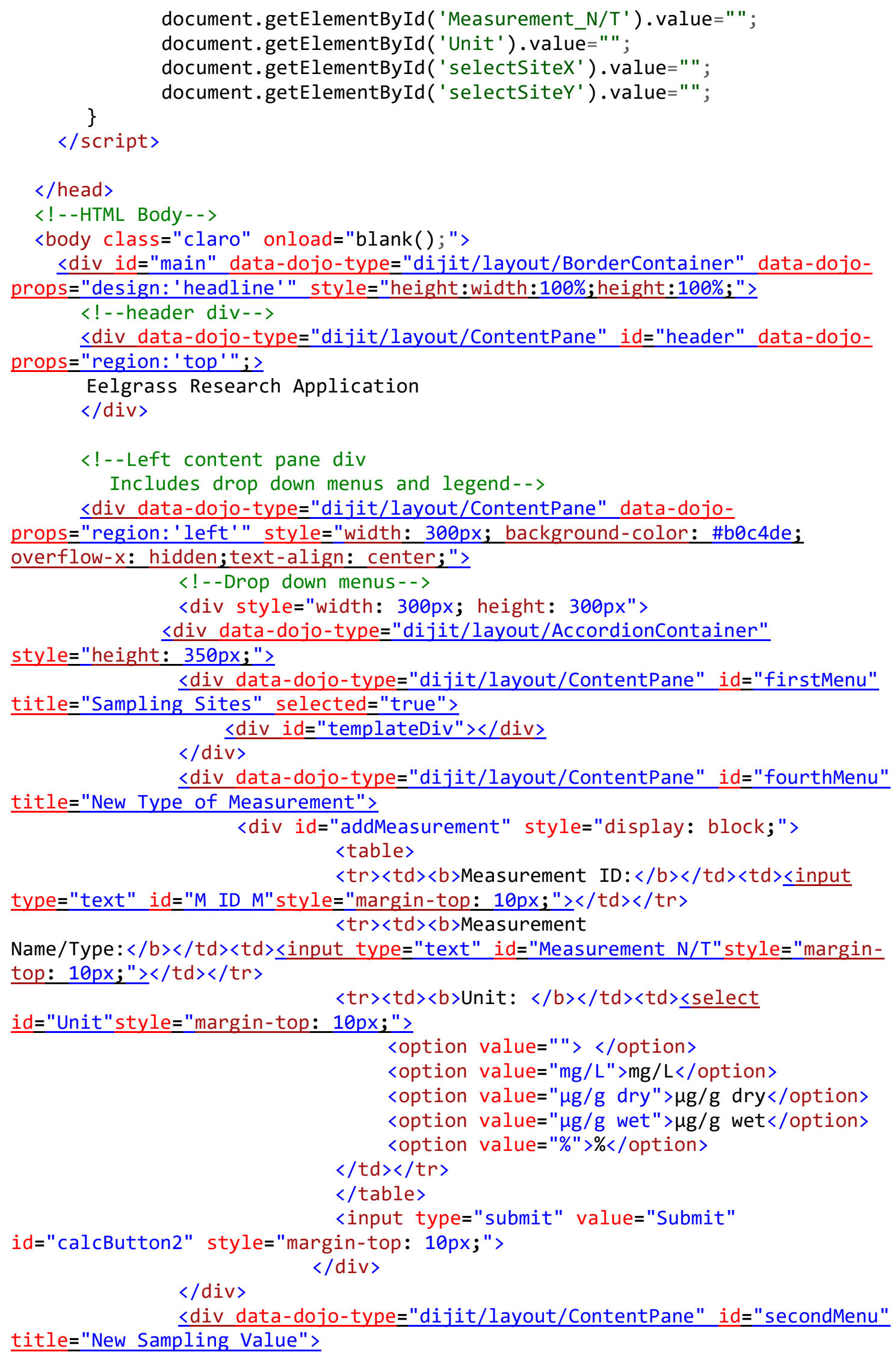




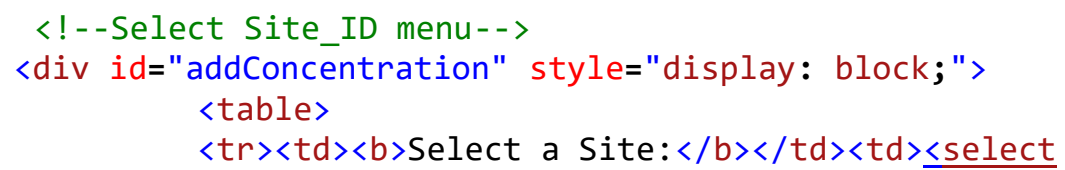




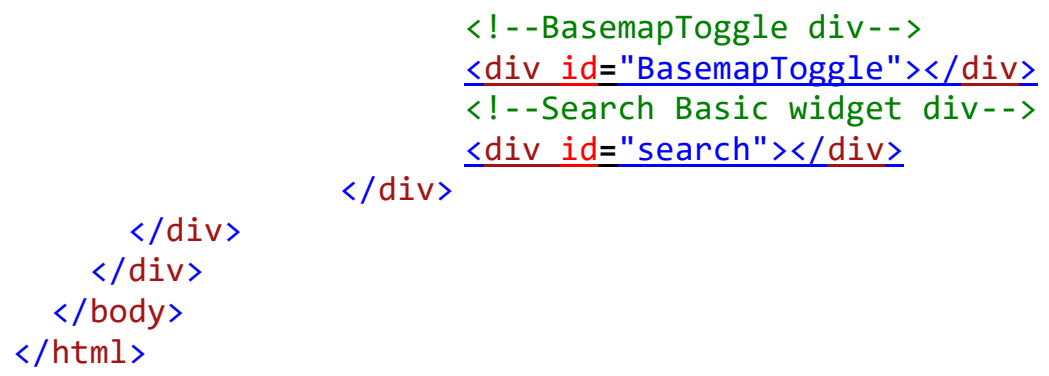




\section{Appendix B: JavaScript Code}

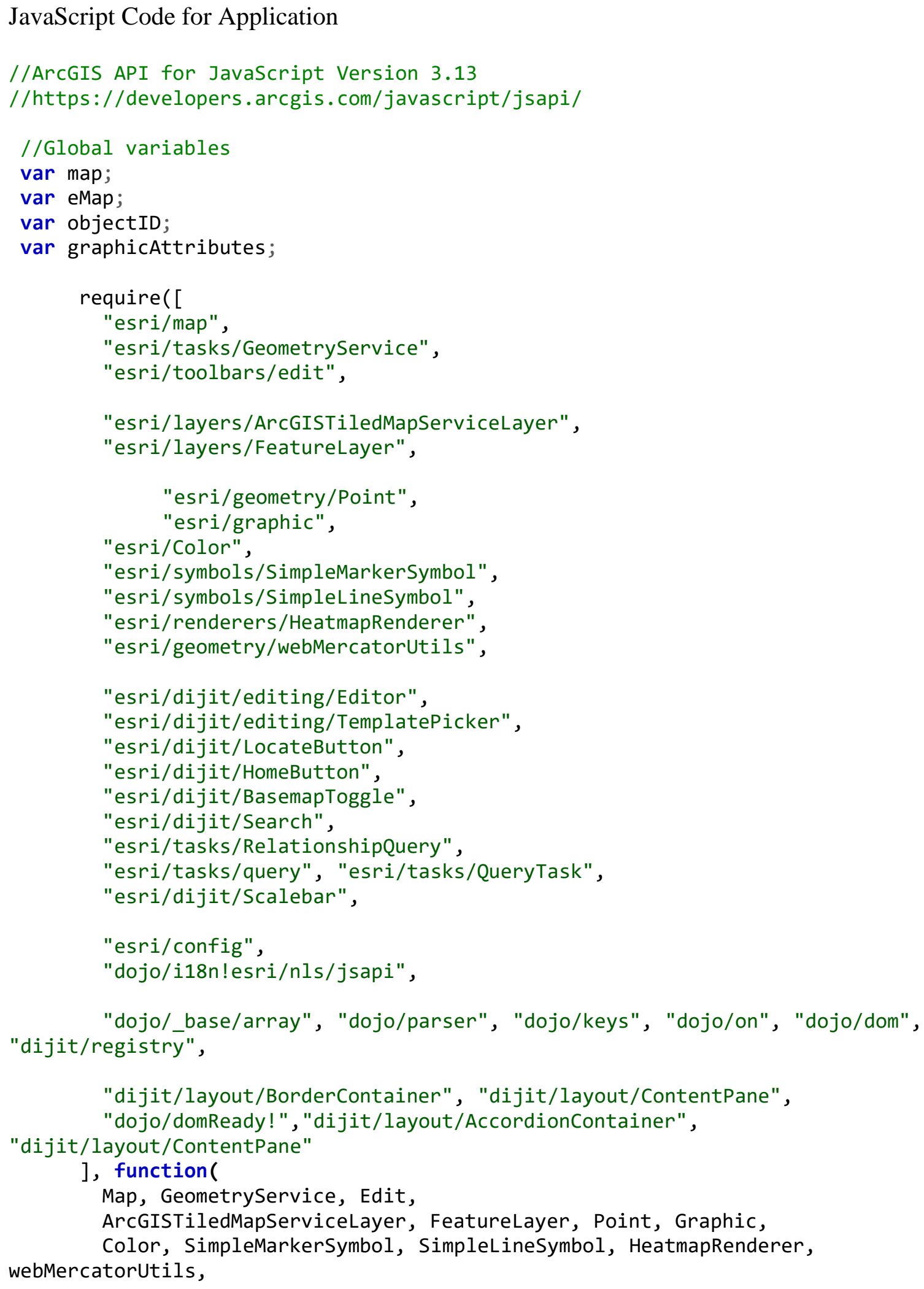


Editor, TemplatePicker, LocateButton, HomeButton, BasemapToggle,

Search, RelationshipQuery, Query, QueryTask,

Scalebar, esriConfig, jsapiBundle,

arrayutils, parser, keys, on, dom, registry

) \{

//The following block of code enables conversion of nodes into other

objects, snapping, and creates a geometry service for development purposes.

parser.parse();

//Enable Snapping

jsapiBundle.toolbars.draw.start = jsapiBundle.toolbars.draw.start +

"<br >Press $\langle b\rangle$ ALT $\langle/ b\rangle$ to enable snapping";

esriConfig.defaults.io.proxyurl = "/proxy/";

esriConfig.defaults.geometryService = new

GeometryService("http://tasks.arcgisonline.com/ArcGIS/rest/services/Geometry/G eometryServer");

etc.)

//Creates a new Map, with settings (basemap, center, zoom extent, created.

//Scalebar, Search Widget, Locator Button, Home Button, Basemap Toggle

//Map is turned on when layers are added.

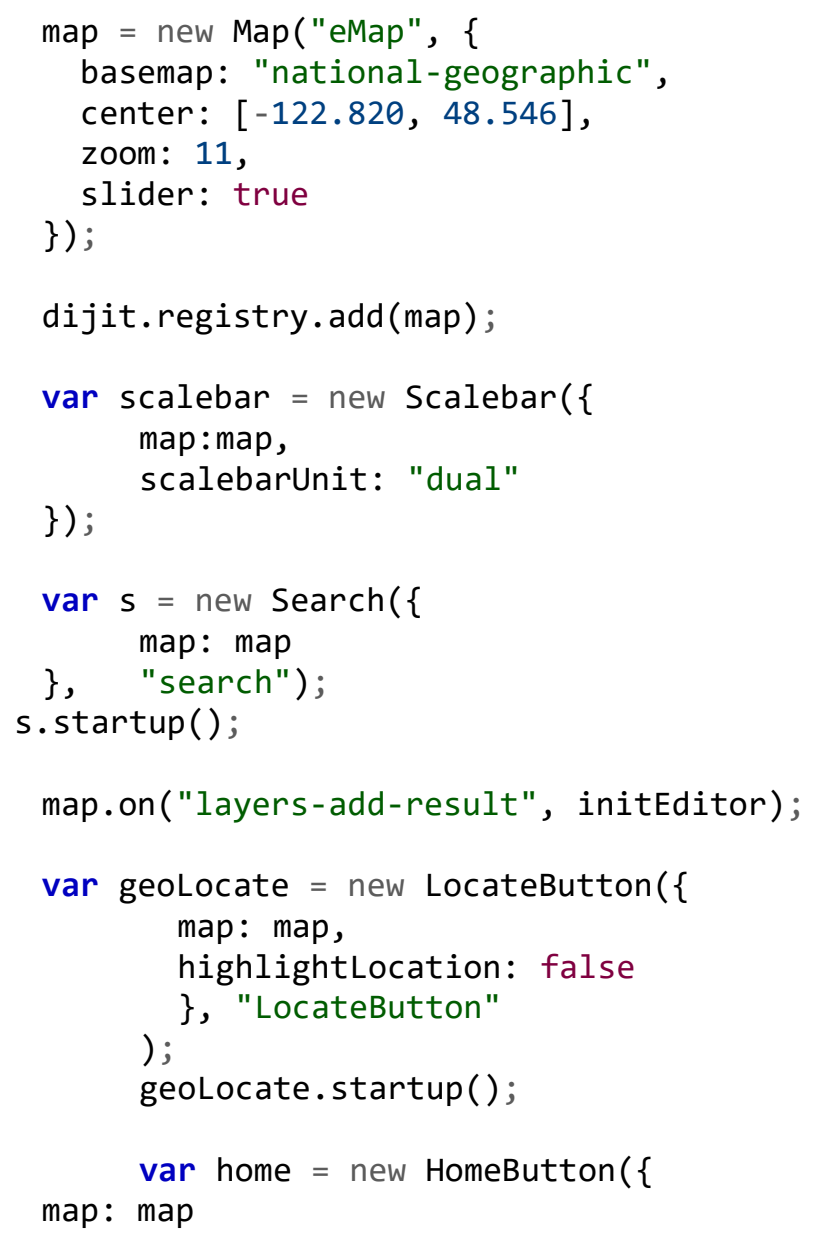




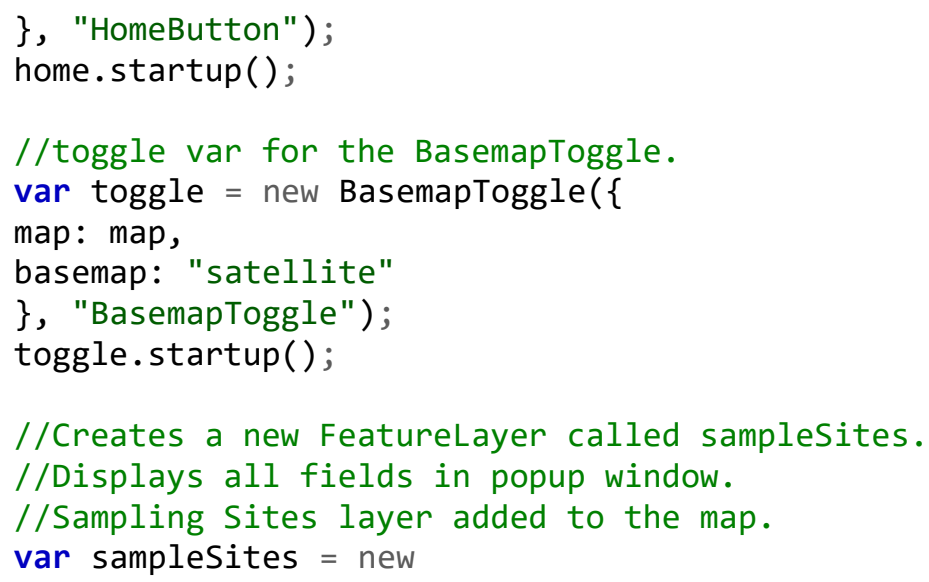

FeatureLayer("http://services.arcgis.com/o6oETlrWetREI1A2/ArcGIS/rest/services /eelgrassDatabase/FeatureServer/2",

\{

mode: FeatureLayer.MODE_ONDEMAND, outFields: ['*'], id: "sampleSites"

\});

map.addLayers ([samplesites]);

//When samplessites point is clicked: iteration through data_tbl. All related records with Site_ID of clicked point will display below legend.

//Concentration and Measurement_ID will show.

//Selected GraphicAttributes of SampleSites are stored in graphicAttributes

//QueryTask through MEASUREMENT and DATA SERVICES. All within the onclick function of a SampleSite. Executes a query operation.

//ResultsData div is blank when each sampling site is selected. sampleSites.on("click", function(evt) \{ graphicAttributes = evt.graphic.attributes; var qyTM = new

QueryTask("http://services.arcgis.com/o6oETlrWetREI1A2/ArcGIS/rest/services/ee lgrassDatabase/FeatureServer/1");

var qyTD = new

QueryTask("http://services.arcgis.com/o6oETlrWetREI1A2/ArcGIS/rest/services/ee lgrassDatabase/FeatureServer/3");

var qyD = new Query ( );

qyD. returnGeometry = false;

qyD.outFields = ["*"];

dojo.byId( "resultsData") . innerHTML=""

//Passing the Site_ID graphicAttribute

//Query Task is excecuted, calling a query through Data table function and function displaying records under legend.

//Empty array object is created.

qyD. where="Site_ID = '" + graphicAttributes.Site_ID + "'";

qyTD.execute (qyD, showResults);

var concentration $=[]$;

//showResults function. This function displays the Site Name and all concentration records associated with the selected sampling site. 
//Measurement_ID and Concentration attributes are added to the concentration array object.

//Query through Measurement layer is excecuted.

function showResults (results) \{ dojo.byId("resultsData"). innerHTML $="\langle b\rangle "+$

graphicAttributes.Site_Name + ": Records $\langle/ b\rangle\langle b r\rangle "$;

var resultcount $=$ results. features. length;

for (var $i=0$; $i<$ resultCount; $i++$ ) \{

var featureAttributes $=$ results.features[i].attributes;

var qyM = new Query ( );

qyM. returnGeometry = false;

qyM.outFields = ["*"];

concentration.push(featureAttributes.Measurement_ID + ", " +

featureAttributes.Concentration);

qyM. where="Measurement_ID = '" +

featureAttributes.Measurement_ID + "'" ;

\}

tmp = qyTM. execute (qyM, showResults 1$) ;$

\}

//Displays Measurement_Name_Type + : + Concentration + Unit (of measurement). Shows "associated" RECORDS on the resultsData div.

function showResults1 (results) \{

var resultCount $=$ results. features. length;

var conc;

for (var $i=0 ; i<$ resultCount; $i++)\{$

var featureAttributes = results.features [i].attributes;

for (var $j=0 ; j<$ concentration. length; $j++)\{$

var $c=$ concentration $[j]$.split $(", ")$;

if $(c[\theta]==$ featureAttributes.Measurement_ID $)\{$ conc $=c[1]$;

\}

break;

\}

dojo.byId("resultsData"). innerHTML $+=$

featureAttributes.Measurement_Name_Type + ": " + conc + " " +

featureAttributes. Unit $+"</ b r\rangle "$;

\}

\}

\});

//TemplatePicker used to allow editing in popup window.

//Editing settings initiated.

function initEditor(evt) \{

var templateLayers = arrayutils.map(evt.layers, function(result) \{ return result.layer;

\});

var templatePicker $=$ new TemplatePicker $(\{$

featureLayers: templateLayers,

grouping: true,

rows: "auto",

columns: 3

\}, "templateDiv");

templatePicker.startup(); 


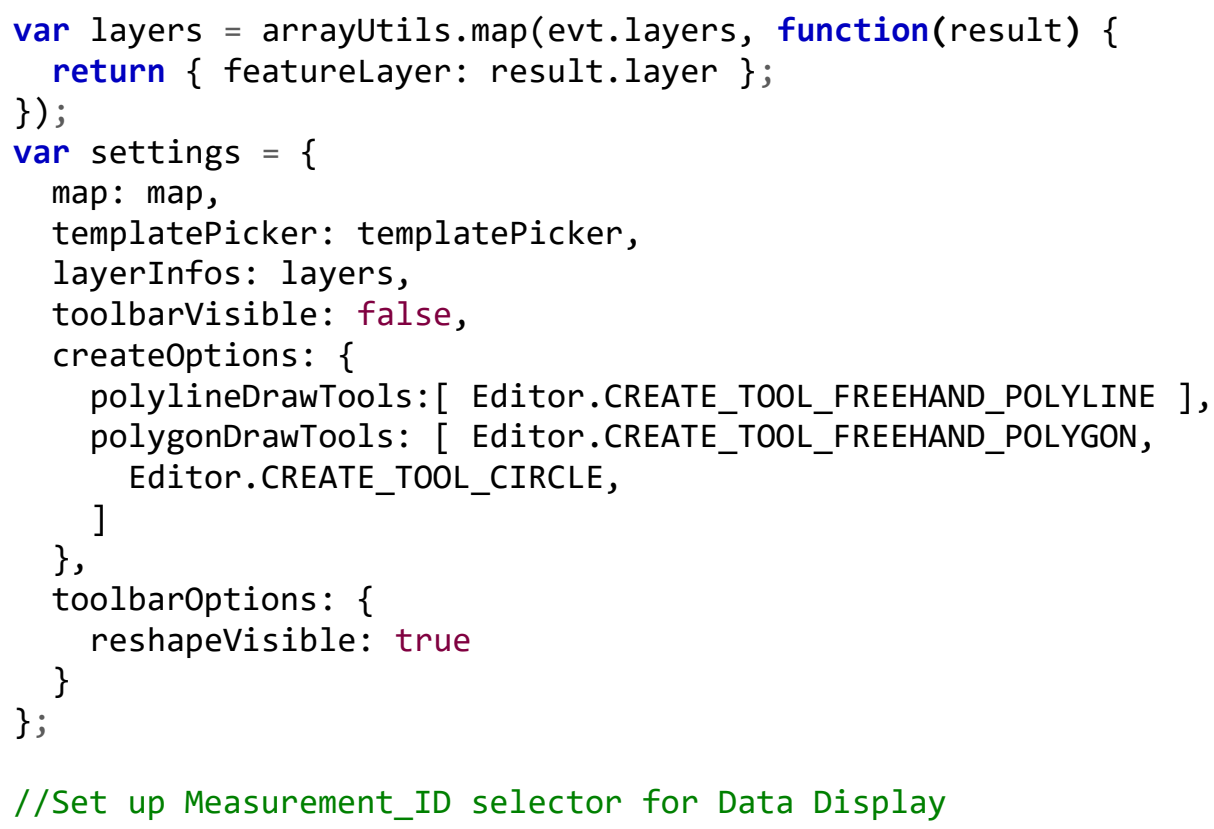


m_ID_QTask.execute(m_ID_Query,function(fSet) \{

var fCount=fSet. features.length;

var m_ID_Options=[];

for (var $\bar{i}=0 ; i<$ fCount; $i++)\{$

$$
x=\{\} \text {; }
$$

$x[$ "label"]=fSet.features[i].attributes.Measurement_ID;

x["value"]=fSet.features[i].attributes.Measurement_ID;

m_ID_Options.push $(x)$;

\}

\});

registry.byId("M_ID").set("options", m_ID_Options);

//Set up Site_ID selector for NEW SAMPLING VALUE

svalueURL="http://services.arcgis.com/o6oETlrWetREI1A2/ArcGIS/rest/services/ee

lgrassDatabase/FeatureServer/2"; //Sample Sites table

sQTask= new QueryTask(svalueURL);

sQuery= new Query ();

sQuery.outFields = ["Site_Name", "Site_ID"];

sQuery. where $=" 1=1 "$,

sQTask.execute(sQuery, function(fSet) \{

var fCount=fSet.features. length;

var siteoptions $=[]$;

for (var $i=0$; $i<f$ Count; $i++)\{$

$\mathrm{X}=\{\}$;

$x["$ label"]=fSet.features[i].attributes.Site_ID;

$x[$ "value"]=fSet.features[i].attributes.Site_ID;

\} siteoptions.push $(x)$;

registry.byId("selectSiteID").set("options", site0ptions);

registry.byId("selectSiteID").on("change", newMeasIDSelect);

\});

var params = \{settings: settings $\}$;

var myEditor = new Editor (params, 'editorDiv');

myEditor.startup();

\}

//Select Measurement_ID, generate HeatMapLayer (Data Display)

//HeatMapLayer is removed if no Observations are found for selected

Measurement_ID

function newMeasIDSelect()

\{

dvalueURL="http://services.arcgis.com/o6oETlrWetREI1A2/ArcGIS/rest/servi

ces/eelgrassDatabase/FeatureServer/3"; //Observation table

dataQTask=new QueryTask (dvalueURL);

dataQuery=new Query( );

dataQuery. outFields =

["Site_ID", "Measurement_ID", "Concentration"]; 
dataQuery.where="Measurement_ID=" "+newValue+" ' AND

Start_Date='" + document.getElementById('from_date').value + "' AND

End_Date='" + document.getElementById('to_date' ').value"' ";

dataQTask. execute(dataQuery, findSites);

var

sitelayer=dijit.registry.byId("eMap").getLayer("heatmapL");

if(typeof sitelayer!='undefined')\{

dijit.registry.byId("eMap").removeLayer(sitelayer);

\}

//findSites function creates a comma separated string of object IDs from Observation table.

//A dynamic layer is created from the selected features of site object IDs.

This layer creates the heat map (data display).

//All selected features are added to the heat map layer as graphics.

//Heat map renderer is created.

function findSites(fSet)

\{

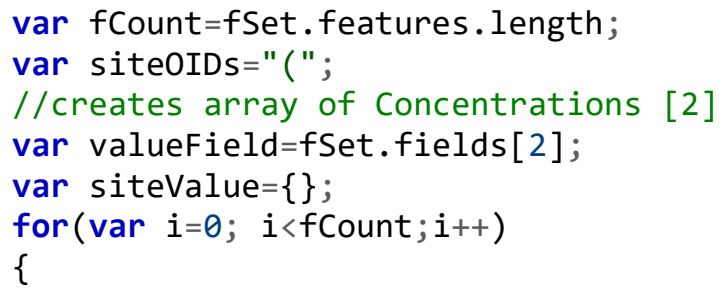

QueryTask("http://services.arcgis.com/o6oETlrWetREI1A2/ArcGIS/rest/services/ee lgrassDatabase/FeatureServer/2"); //Sites Layer siteQuery=new Query();

res.geometryType, "fields": [res.fields[0], valueField]\}; var fCollection $=\{$ "layerDefinition": layerDef,

"featureSet": \{"features":[],"geometryType": res.geometryType\}\}; var tmpWD=dijit.registry.byId("eMap"); var selectedFeatures=new

FeatureLayer(fCollection, \{id: "heatmapL", mode: FeatureLayer.MODE_SNAPSHOT \}); var features $=[]$;

for (var $i=0 ; i<$ siteCount $i++)$ 


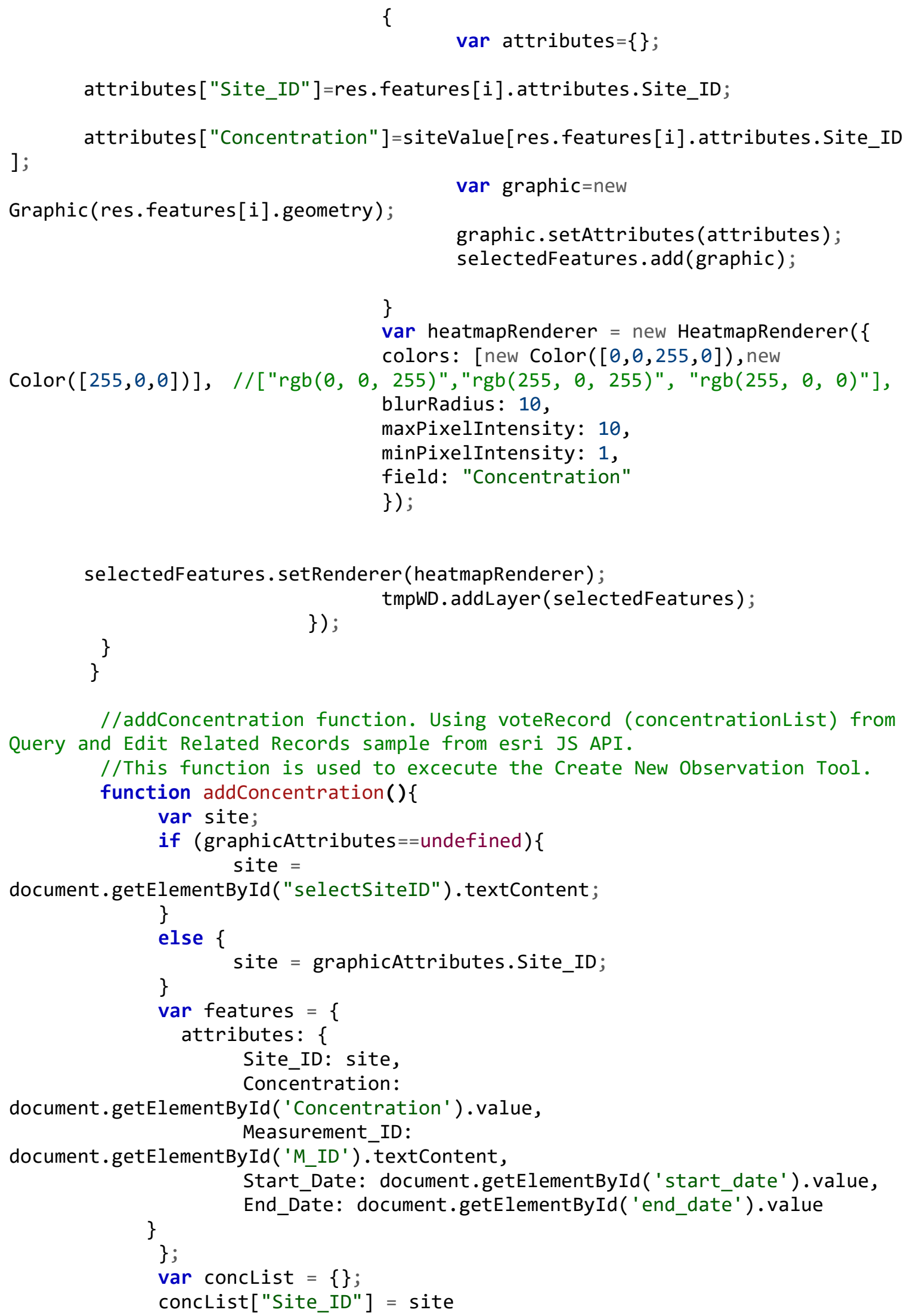




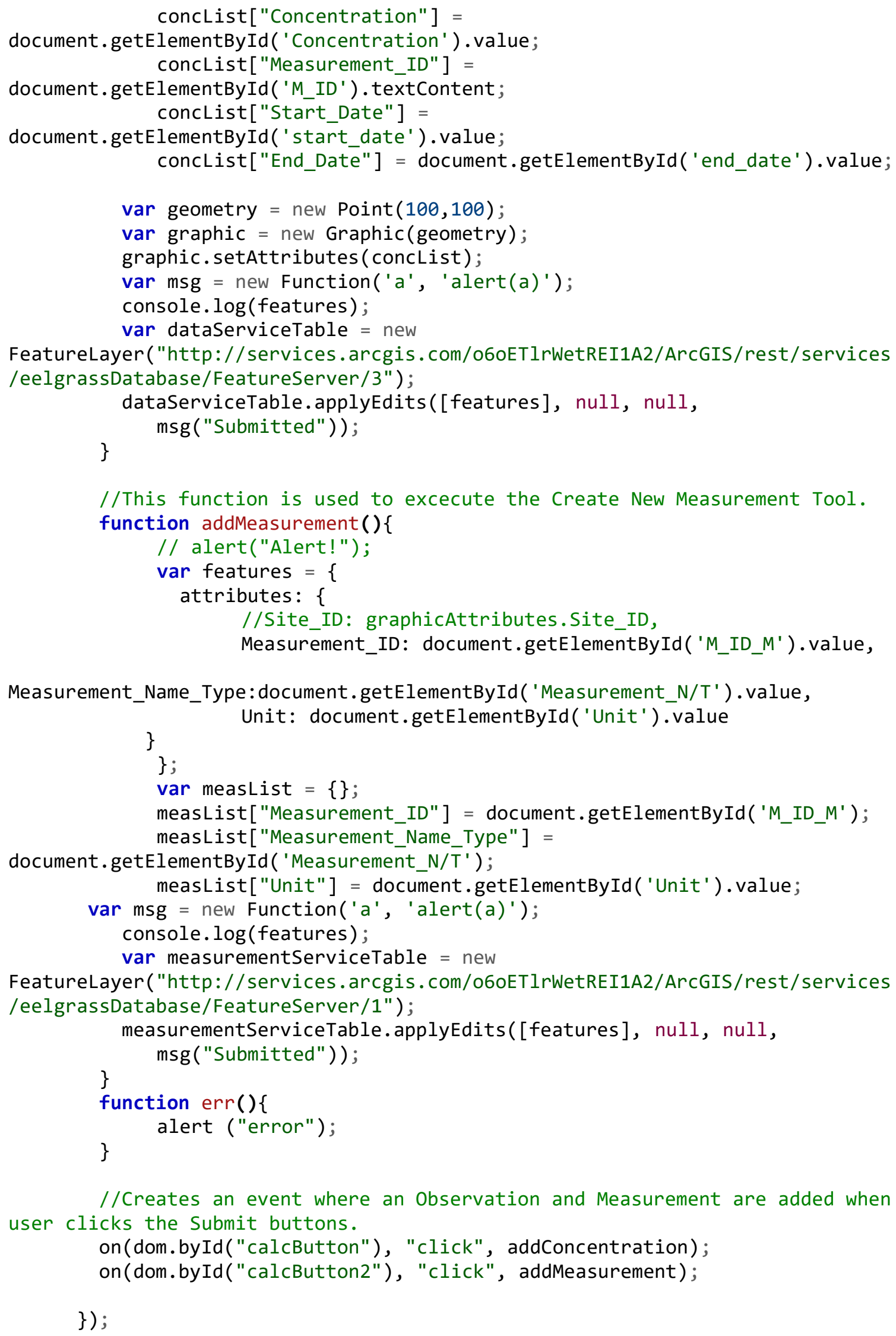




\section{Appendix C: CSS Code}

CSS Code for Application

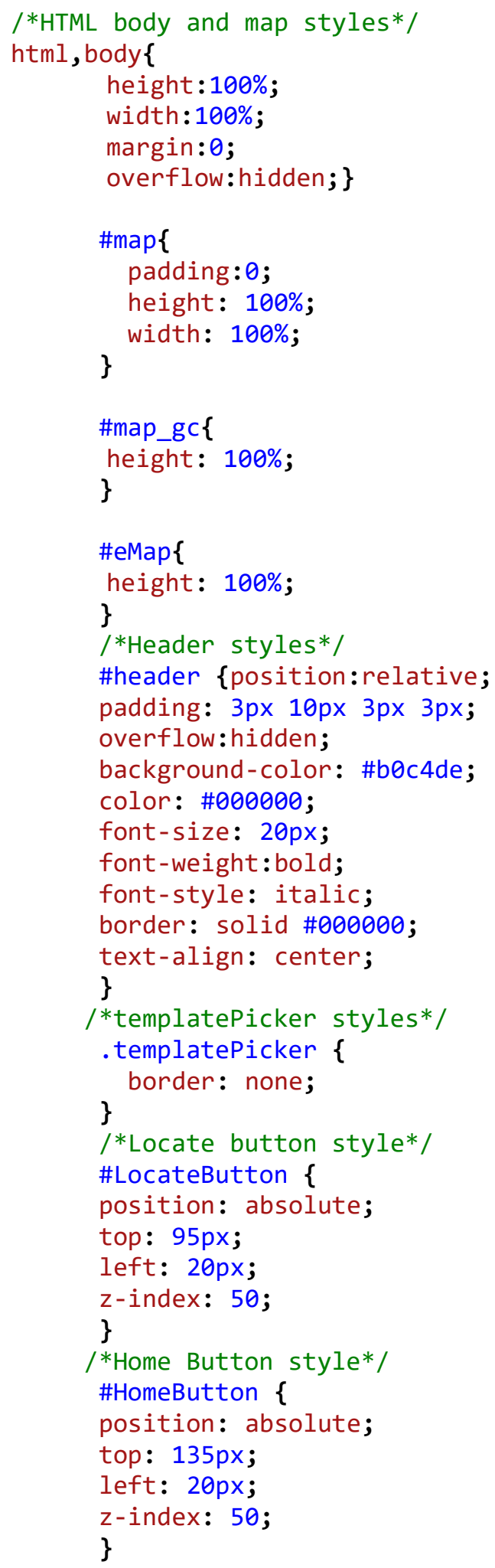




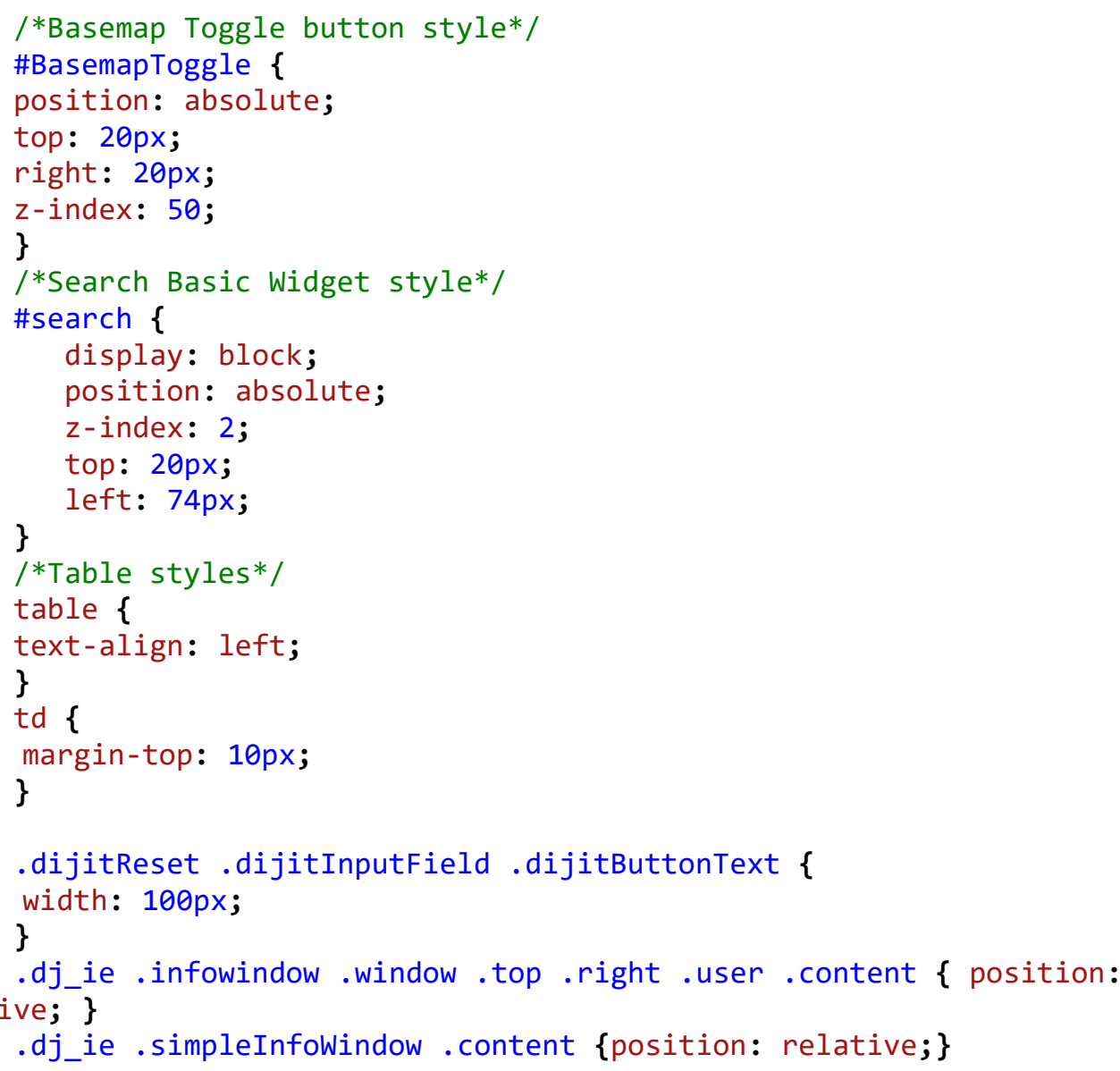

